\title{
Numerical Investigation of the Influence of Rockfall near Structures in Selected Southwestern States, Nigeria
}

\author{
Oniyide G.O*, Omoegun S.O \\ Department of Mining Engineering, Federal University of Technology, Akure, Ondo State, Nigeria \\ *Corresponding Author: Oniyide G.O, Department of Mining Engineering, Federal University of \\ Technology, Akure, Ondo State, Nigeria
}

\begin{abstract}
Influence of rock fall in rocky and hilly area located near structures within Southwestern Nigeria was investigated. In this study, seven highly susceptible rock fall prone locations near structures were selected, RocFall 8.0 (RocScience software) was used for numerical simulation model and landslide intensity hazard level values/zones to predict the influence of rock fall. Rock fall movement trajectory and bounce height were modeled with their corresponding translational velocity and kinetic energy for predicting the influence of rock fall. Location 6 has the maximum bouncing height of $26.3 \mathrm{~m}$ and location 4 has the minimum bouncing height of $1.9 \mathrm{~m}$ as compared to other locations. The results of the rock fall impact simulation model predict that the study location 1, 2, 3, 5, 6 and 7 has respectively, total kinetic energy of approximately $61.2 \mathrm{~kJ}, 81.3 \mathrm{~kJ}, 42.1 \mathrm{~kJ}, 92.1 \mathrm{~kJ}, 92.6 \mathrm{~kJ}$ and 65,9 kJ which pose risk of medium intensity hazard level zone, while study location 4 which has total kinetic energy of $27.9 \mathrm{~kJ}$ pose risk of low intensity hazard level zone. In conclusion the research was able to predict the influence/magnitude of damage of rock fall near structure base on rock fall landslide intensity hazard classification. It is recommended that further research should be done in all parts of the country to establish rock fall hazard map for Nigeria. The residents of this study area should be cautious of rock fall occurrence capable of causing mortality and damaging structures, hence, barriers with capacity > $300 \mathrm{~kJ}$ are required to prevent rock fall vulnerability/consequence in the study area.
\end{abstract}

\section{INTRODUCTION}

Lee and Elliot (1998), defined that a rock fall is the down slope movement of boulders (in case of natural slopes) or rock blocks (in cut slopes) which has the potential to destroy or damage the structures along its path or create an obstacle to public transportation networks, if not properly strained (i.e when inadequately managed, rock falls present a major hazard to any surrounding structures).

Rockfall is a widespread phenomenon in mountain environments where it threatens human beings and poses significant challenges to infrastructure, industry and housing (Volkwein et al., 2011). Despite the fact that the process itself usually involves rather limited volumes, rockfall phenomena can nevertheless result in economic losses due to service interruptions and equipment damage, as well as to injury or death of users and operators of these facilities. As a consequence, rockfall protection via both structural and land use planning actions is an important issue for administrators and stakeholders in areas affected by rockfall (Agliardi et al., 2009).

However, predicting the rockfall runout distance and propagation areas, i.e., the areas potentially threatened by rockfall, is still a challenge (Jaboyed off and Labiouse, 2011).

Landslides, rockfalls, and rock avalanches are associated with almost instantaneous collapse and spreading (Legros, 2002; DeBlasio and Crosta, 2015), due to their high mobility, threatening populated areas located even far away from the slope source (Crosta et al., 2005; Zhou and Cheng 2013). its occurrence had been attributed with loss of life and huge monetary loss (Ansari et al., 2018).The recent occurrence of rock falls and the alarming rate of change in land use as a result of the rapid growth in population and development with the needs of siting residential buildings and other structures in rocky/hilly areas prone to rockfall calls for research of this kind in Nigeria. Good knowledge and better understanding of rock fall phenomenon is important in order to adequately 
Numerical Investigation of the Influence of Rockfall near Structures in Selected Southwestern States, Nigeria

investigate the influence of rock fall near structures because rockfall disasters/hazard have been a subject of intensive research due to their significant destructive power.

Major causes of rockfall are rainfall, frost, discontinuities, differential erosion, animal dens etc. whereas minor causes are tree roots, springs, vehicle vibrations and rock weathering (Ahmad et al., 2012).

As stated by Jaboyed off et al. (2005), the design of protection measures and rockfall hazard zoning require data on three basic characteristics of rockfalls, namely the number of passing rocks per time unit, impact energy, and impact height. That is, information is required on the mass and velocity of the fall to determine the energy capacity and on the location of impact points, trajectory paths, and runout distances so as to determine danger zonation or the optimum location and dimensioning of defense structures (e.g., barriers or fences).

The performance of a rockfall protection barrier is usually expressed in terms of the maximum energy capacity they are able to absorb. Since the dissipation of energy is accomplished through the accumulation of permanent deformations of the system, the rating of the barrier can be defined also in terms of its deformability. The greater the barrier capacity, the higher its plastic compliance

Bourrier and Hungr (2013), established three different typologies of barrier physical behavior to stop falling rock, the first one consists of static barriers, which are composed by rigid elements that employ their high inertia to stop the rock (e.g, walls of concrete or gabions, formed by metal profiles and earth ridges), the second type corresponds to dymac barriers of static deformation, having a reduced capacity of energy absorption (below 150-200 kJ), which are mainly used as energy dissipators elements in docks with shock absorbers, while the third can be found as dynamic barriers of plastic deformation characterized by current absorption capacity of $8.000 \mathrm{~kJ}$, using special elements that deform and tear for dissipating this high energy, so that they must be replaced after an impact. Of these three typologies, the latter is the most often used nowadays.

Depending on the initiation of the detached rock block and the geomorphic conditions of the slope, a rockfall trajectory is the combination of three main processes, namely: sliding or rolling, free falling and impact. These processes are controlled by well-known physical laws and can be described by simple equations and hence easily simulated if these processes are free of fragmentation. However, if fragmentation occurs during the rock falling, the process will be much more complicated to simulate.

Generally, there are two approaches to evaluate rock fall dynamics, which are experimental methods and numerical analyses (Agliardi and Crosta 2003; An and Tannant 2007; Bozzolo and Pamini 1986; Crosta and Agliardi 2003; Dorren 2003; Giacomini et al. 2009; Giani et al. 2004; Mougin et al., 2005; Nocilla et al., 2008). Experimental methods include field tests and empirical studies. Usually, field tests are carried out to determine rockfall trajectories and runout distances, and sometimes to evaluate the efficiency of protective measures.

Field test is undoubtedly effective, but it is expensive and time consuming. It is also impossible to test many scenarios such as, initial conditions (velocity, mass, location), natural and design topography and ground properties. Therefore, field tests are typically used to calibrate numerical models. By using the calibrated numerical models, statistical and parametric analyses may be performed to improve the understanding of rock fall events.

Numerical analysis mainly focuses on the evaluation of the trajectories of detached blocks for different morphological and geologic conditions. It becomes increasingly popular and powerful because of the development of computer technology and relevant information technology.

Several computer programs either in 2D and 3D have been developed and tested for rock fall analysis (Guzzetti et al. 2002). Most of the programs implement either a lumped mass or a rigid body approach.

Raetzoet al. (2002) developed a chart of the extent of danger in order to establish a similar and uniform means of assessing the various kinds of natural hazards affecting Switzerland. In the study, intensity and frequency/return period (probability) were the major parameters used to define the three degrees of dangers which are: i. High intensity, ii. Medium intensity, iii. Low intensity. The magnitude of damage that could be induced by an event is based on the classification of threshold values for degrees of dangers. 
Numerical Investigation of the Influence of Rockfall near Structures in Selected Southwestern States, Nigeria

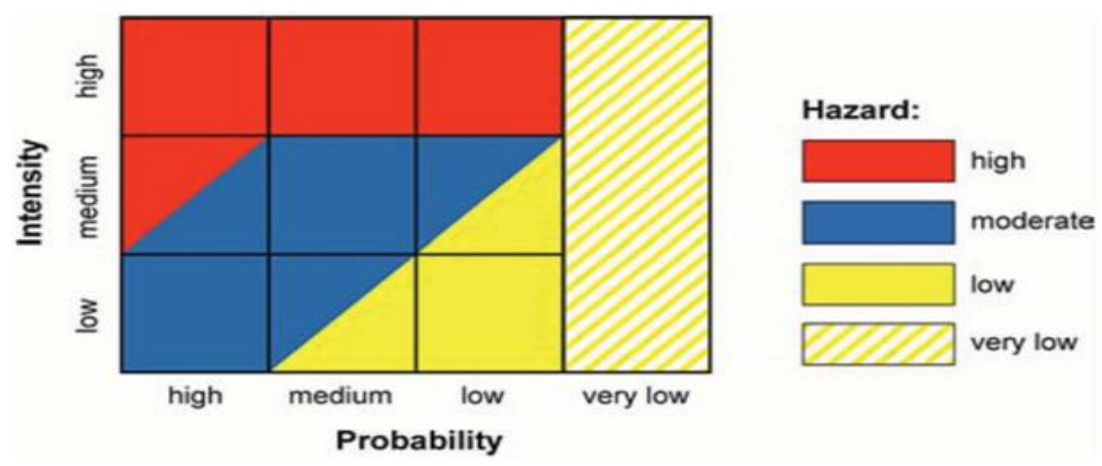

Figure1: Diagram of hazard levels as a function of probability and intensity Lateltin et al. (2005).

Lo et al. (2018), in their study further group landslide intensity values using different criteria to predict the magnitude of damage that could be induced based on the classification of threshold values for degrees of dangers.

Table1: Criteria for landslide intensity values (Lo et al., 2018)

\begin{tabular}{|c|c|c|c|c|}
\hline \multirow[t]{2}{*}{ Process } & \multicolumn{4}{|c|}{ Intensity } \\
\hline & Very low & Low & Medium & High \\
\hline $\begin{array}{l}\text { Rock falls } \\
\text { Kinetic energy }\end{array}$ & $<3 \mathrm{~kJ}$ & $3-30 \mathrm{~kJ}$ & $30-300 \mathrm{~kJ}$ & $>300 \mathrm{~kJ}$ \\
\hline $\begin{array}{l}\text { Slides } \\
\text { Mean annual velocity } \\
\text { Displacement }\end{array}$ & $\begin{array}{l}- \\
-\end{array}$ & $\begin{array}{l}<2 \mathrm{~cm} / \text { year } \\
-\end{array}$ & $\begin{array}{l}2-10 \mathrm{~cm} / \text { year } \\
-\end{array}$ & $\begin{array}{l}>0.1 \mathrm{~m} / \text { day } \\
>1 \mathrm{~m} / \text { event }\end{array}$ \\
\hline $\begin{array}{l}\text { Debris flow } \\
\text { Debris front thickness } \\
\text { Debris front } \\
\text { Depth of soil material (potential debris flow) }\end{array}$ & $\begin{array}{l}- \\
- \\
0.5 \mathrm{~m}\end{array}$ & $\begin{array}{l}- \\
- \\
1 \mathrm{~m}\end{array}$ & $\begin{array}{l}<2 \mathrm{~m} \\
<5 \mathrm{~m} / \mathrm{s} \\
1-2 \mathrm{~m}\end{array}$ & $\begin{array}{l}>2 \mathrm{~m} \\
>5 \mathrm{~m} / \mathrm{s} \\
>2 \mathrm{~m}\end{array}$ \\
\hline
\end{tabular}

This study predicts the influence of rockfall based on the magnitude of damage to near structures using landslide intensity hazard level values. Seven locations in Ekiti, Ogun and Ondo States which lies in South-Western region in Nigeria were used as the study area, the study locations lie between latitude and longitude: $7^{\circ} 16^{\prime} 31.74^{\prime \prime} \mathrm{N}$ and $5^{\circ} 14^{\prime} 37.10^{11} \mathrm{E}, 7^{\circ} 06^{\prime} 57.73^{\prime \prime} \mathrm{N}$ and $5^{\circ} 06^{\prime} 35.92^{\prime \prime} \mathrm{E}, 7^{\circ}$ 29' 56.85" $\mathrm{N}$ and $5^{\circ} 13^{\prime} 54.80^{\prime \prime} \mathrm{E}, 7^{\circ} 37^{\prime} 53.77^{\prime \prime} \mathrm{N}$ and $5^{\circ} 13^{\prime} 23.25^{\prime \prime} \mathrm{E}, 7^{\circ} 10^{\prime} 45.97^{\prime \prime} \mathrm{N}$ and $3^{\circ} 21^{\prime}$ 35.87" E, 7 $7^{\circ} 11^{\prime} 9.10^{\prime \prime} \mathrm{N}$ and $3^{\circ} 20^{\prime} 35.21^{\prime \prime} \mathrm{E}, 7^{\circ} 9^{\prime} 37.08^{\prime \prime} \mathrm{N}$ and $3^{\circ} 21^{\prime} 4.65^{\prime \prime} \mathrm{E}$ (NGSA) (Figure 34).

\section{MATERIALS AND METHOD}

Materials used for field data acquisition are; Global Positioning System (GPS), measuring tape, stop watch, objects of different shape, a field book. Rocscience software (RocFall 8.0) was used for the Result analysis.

\subsection{Method}

The research methodology involves, rock fall distance and time taking to cover the distance measurement, elevation and coordinate measurement, other physical measurements and observations in the study areas. The data from the field were then analyzed.

\subsection{Field Work Procedure}

Outcrop near structural buildings that is characterizes with hanging rocks were selected across the whole location for this study. Distance between the outcrop and the nearest building was obtained using the measuring tape. The Global Positioning System was used to obtain the coordinates and the elevation. Stop watch was used to measure the time taking for the objects to move from the top of the slope to the end location of the slope. All data obtained were recorded in the field book.

\subsection{Data Analysis}

Parameters for rock fall simulation were determined by rigorous field study and laboratory experiments. Rock fall modeling was carried out using RocFall program 8.0. Lumped mass-modeling program was selected as it considered rock block to be a simple point with rock mass concentrated at 
the center of gravity. The assumed point mass is then released down the observation slope. As soon as the rock block collides with the slope surfaces, normal and tangential velocities to the slope are reduced to normal coefficient of restitution $(\mathrm{Rn})$ and tangential coefficient of restitution (Rt). These coefficients of restitution depend upon rock type and slope morphology. Along with the coefficient of restitution, RocFall 8.0 program considers the angular velocity of the rock block and surface roughness. The RocFall program also help in determining remedial measures by computing kinetic energy and location of impact on a barrier at the same time determine the capacity, size and location of barriers. Incompatibility of the results file was avoided by exporting all results obtained from the rock fall model in JPEG image format.

\section{RESULTS AND DISCUSSION}

\subsection{Rock Fall Modelling}

For each of the seven locations selected for this study, a computer simulation has been run using the program Rocfall 8.0 (RocScience, 2018). The natural variability of site conditions that includes irregularly shaped blocks of rock, and slope roughness were taking into account for the modelling of the rock falls. The material types used in the analysis was rock for the entire slope, it is assumed that all rock falls originated higher on the top of the slope, so the seeder velocities have values that generate trajectories that are consistent with observed field conditions. The model was performed with a typical seven rock falls. These analyses demonstrate the operation and results of the program.

Figure 2 to 5 show the rock fall modeling results of study location 1

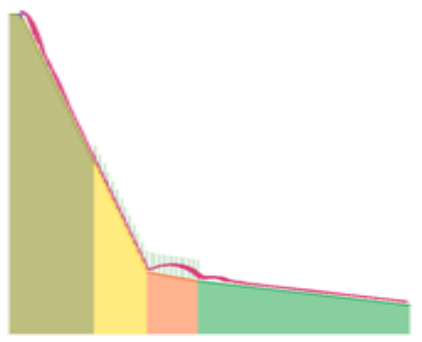

Figure2: Simulation of seven rock fall model

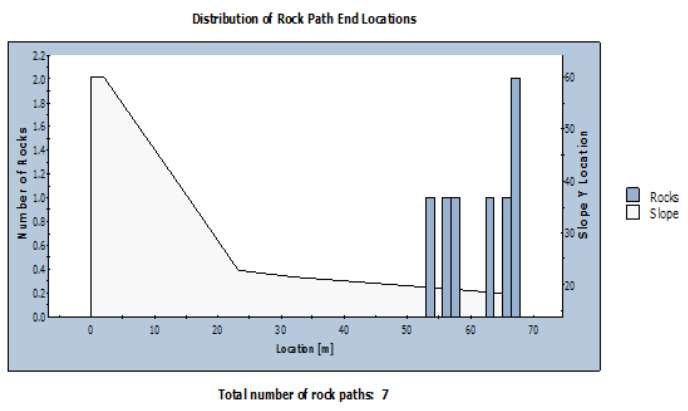

Figure3: Rock fall end location from RocFall 8.0 simulated results

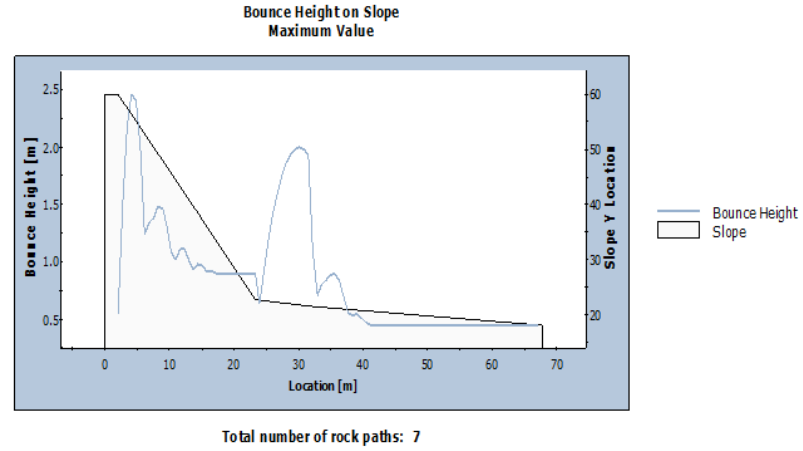

Figure4: Trajectory height envelope from RocFall 8.0 simulated results 
Numerical Investigation of the Influence of Rockfall near Structures in Selected Southwestern States, Nigeria

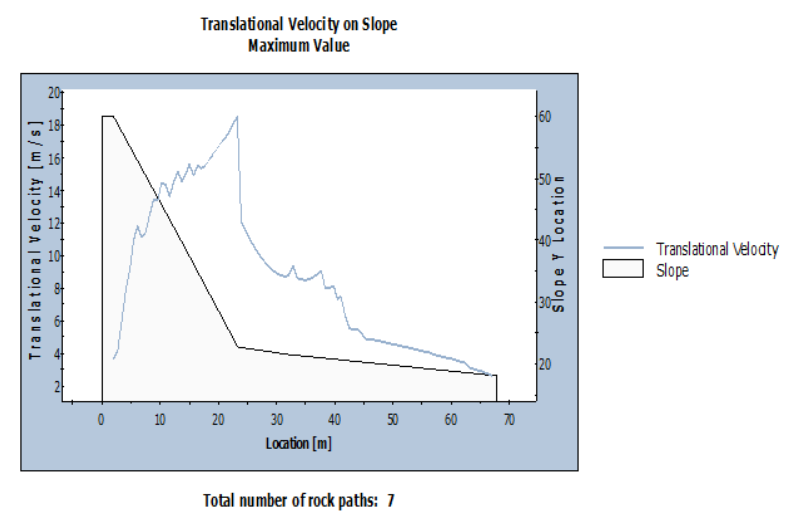

Figure5: Trajectory translational velocity envelope from RocFall 8.0 simulated results

Figure 6 to 9 show the rock fall modeling results of study location 2 .

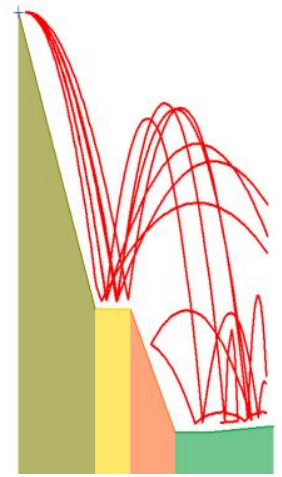

Figure6: Simulation of seven rock fall model

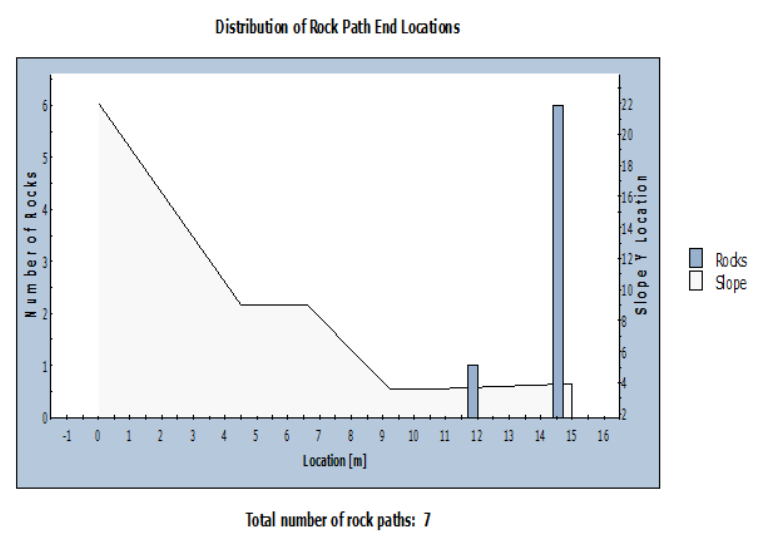

Figure7: Rock fall end location from RocFall 8.0 simulated results

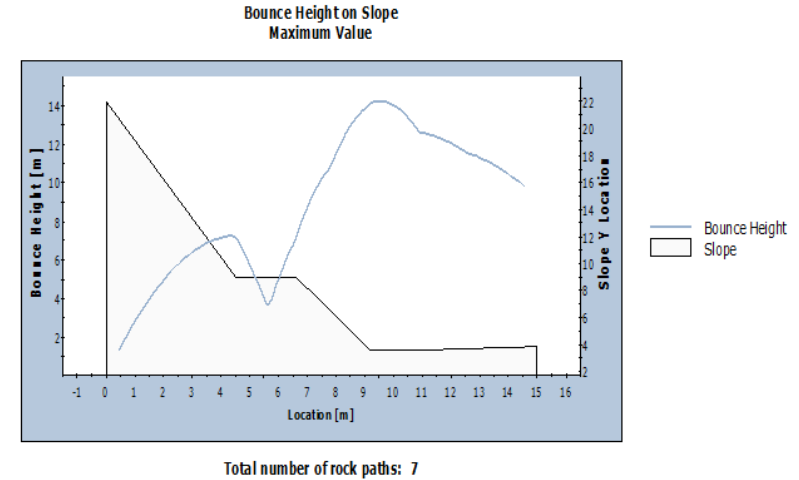

Figure8: Trajectory height envelope from RocFall 8.0 simulated results 
Numerical Investigation of the Influence of Rockfall near Structures in Selected Southwestern States, Nigeria

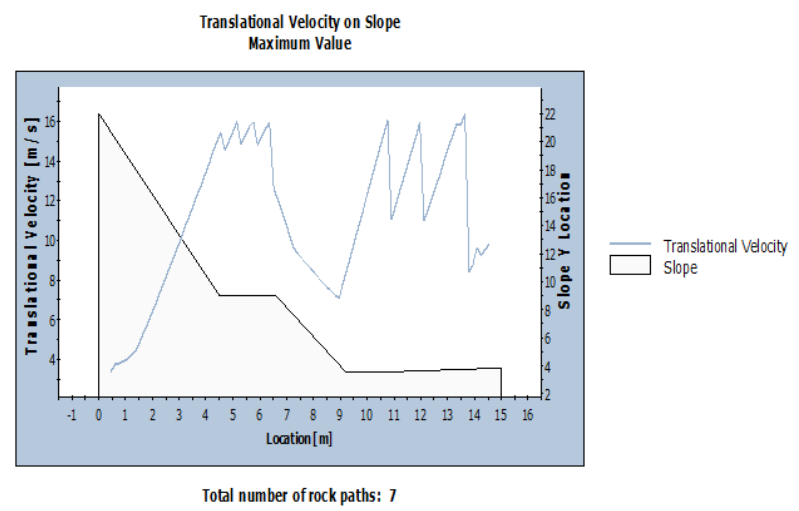

Figure9: Trajectory translational velocity envelope from RocFall 8.0 simulated results

Figure 10 to 13 show the rock fall modeling results of study location 3 .

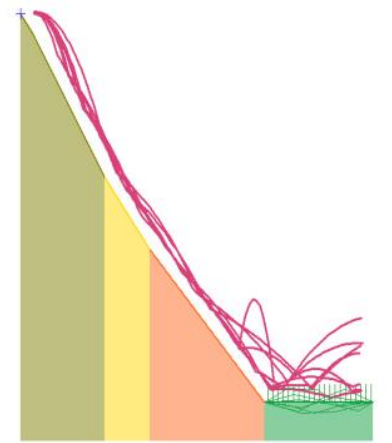

Figure10: Simulation of seven rock fall model

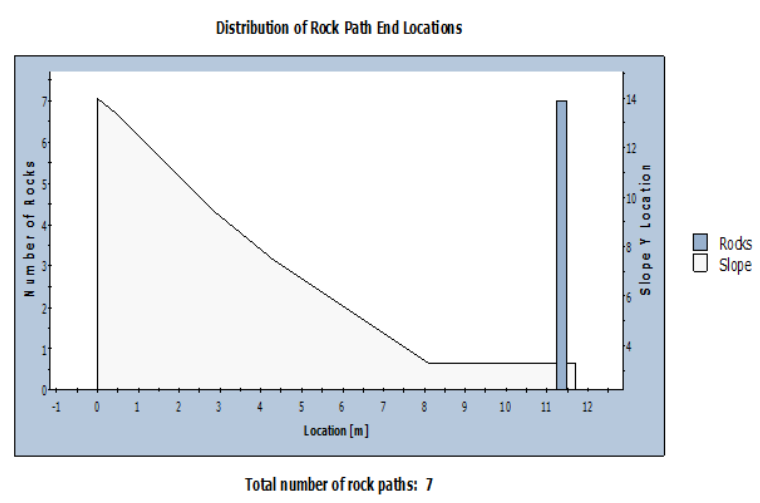

Figure11: Rock fall end location from RocFall 8.0 simulated results

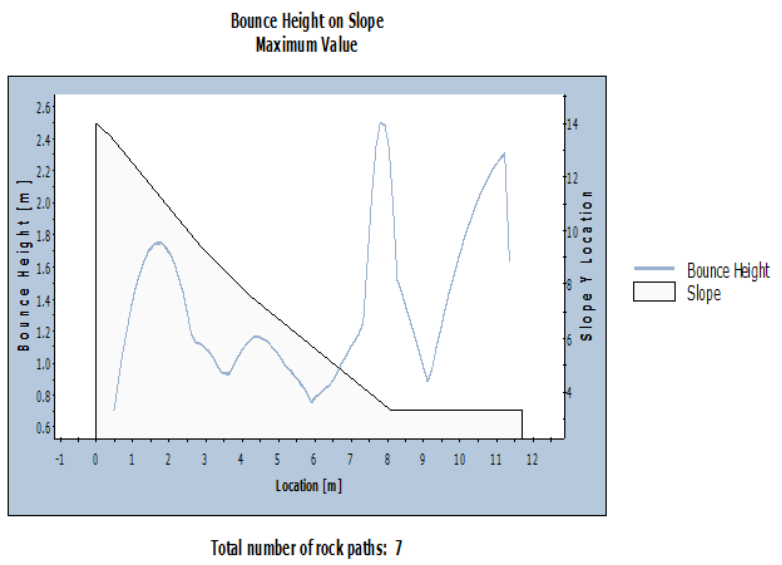

Figure12: Trajectory height envelope from RocFall 8.0 simulated results 
Numerical Investigation of the Influence of Rockfall near Structures in Selected Southwestern States, Nigeria

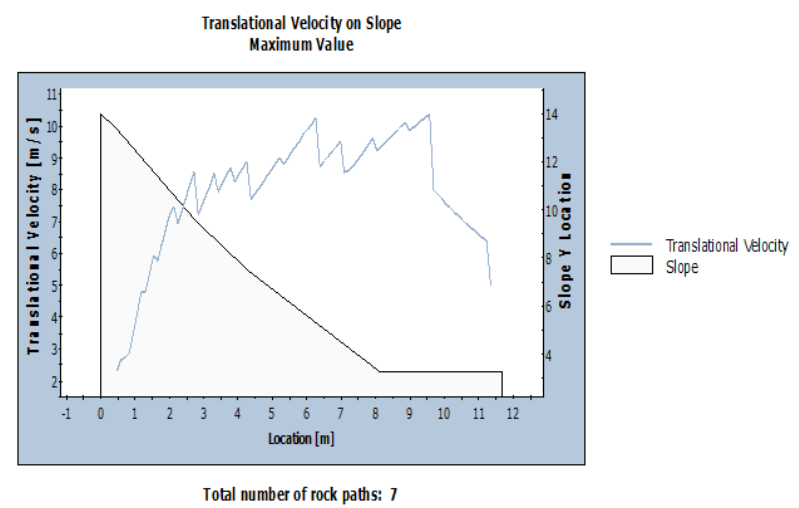

Figure13: Trajectory translational velocity envelope from RocFall 8.0 simulated results Figure 14 to 17 show the rock fall modeling results of study location 4.

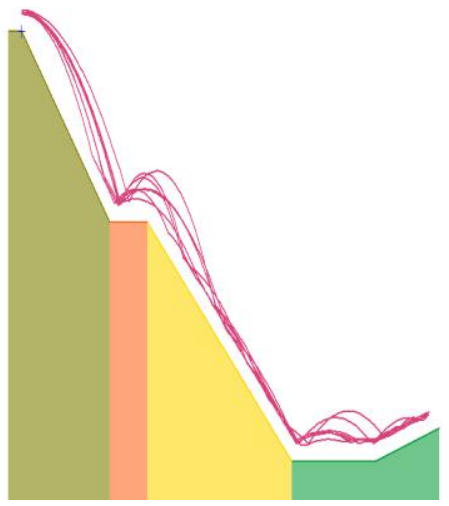

Figure14: Simulation of seven rock fall model simulated

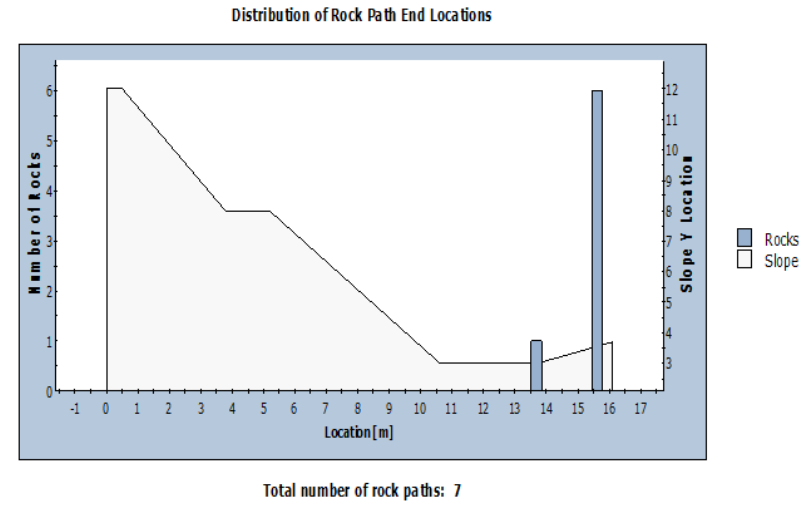

Figure15: Rock fall end location from RocFall 8.0 results

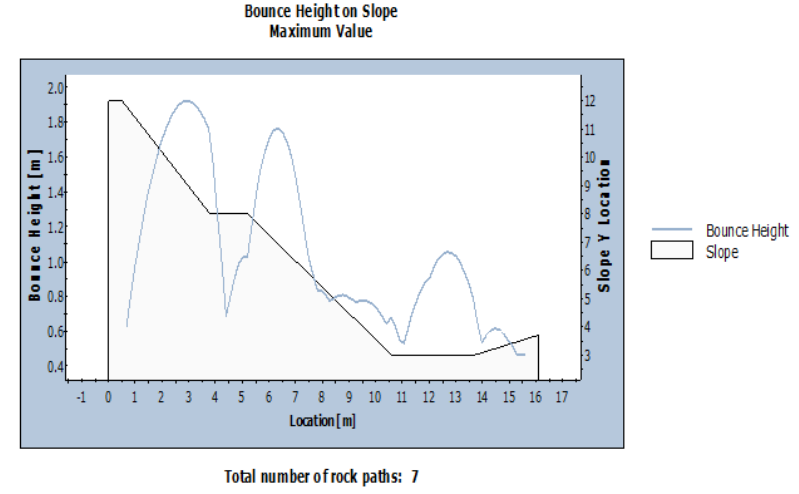

Figure16: Trajectory height envelope from RocFall 8.0 simulated results 
Numerical Investigation of the Influence of Rockfall near Structures in Selected Southwestern States, Nigeria

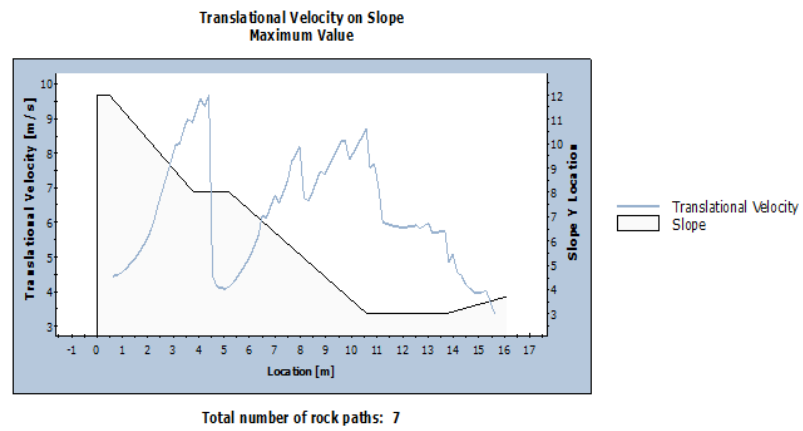

Figure17: Trajectory translational velocity envelope from RocFall 8.0 simulated results

Figure 18 to 21 show the rock fall modeling results of study location 5 .

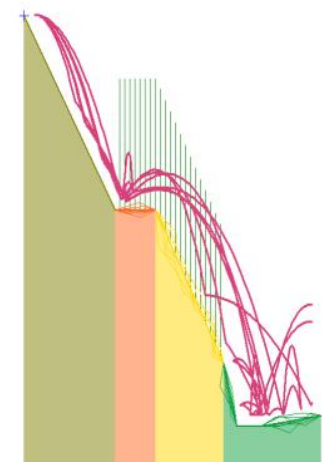

Figure18: Simulation of seven rock fall model

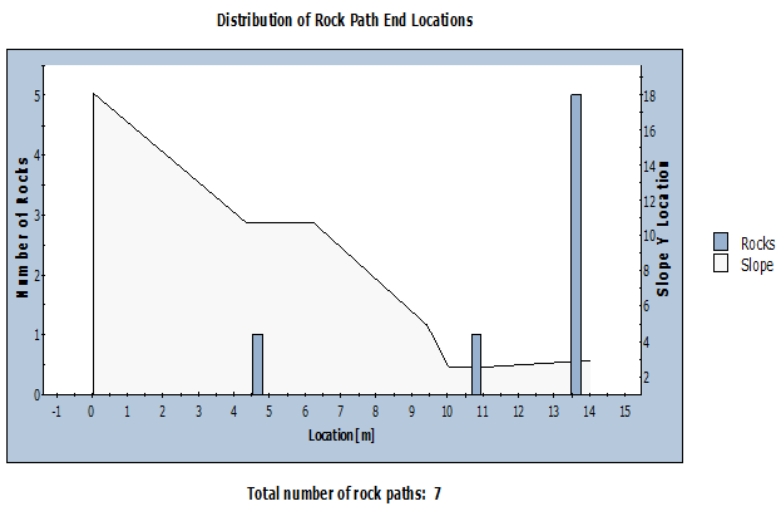

Figure19: Rock fall end location from RocFall 8.0 simulated results

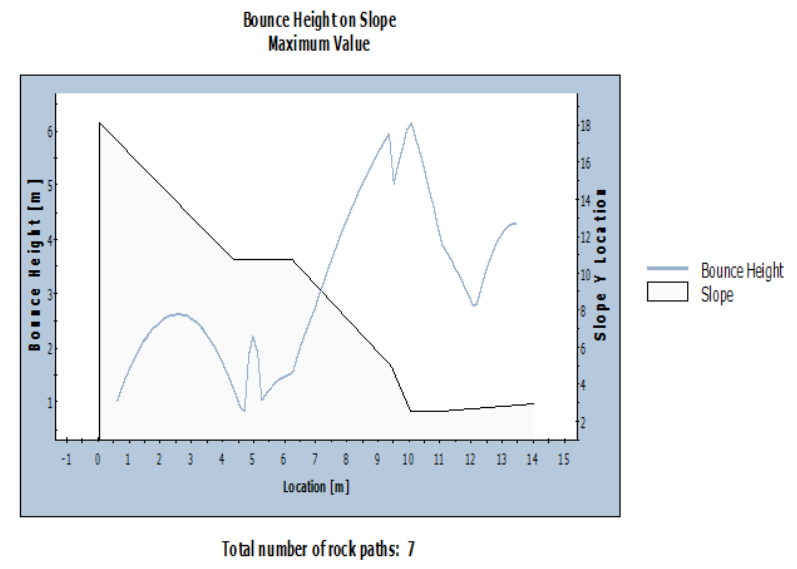

Figure20: Trajectory height envelope from RocFall 8.0 simulated results 
Numerical Investigation of the Influence of Rockfall near Structures in Selected Southwestern States, Nigeria

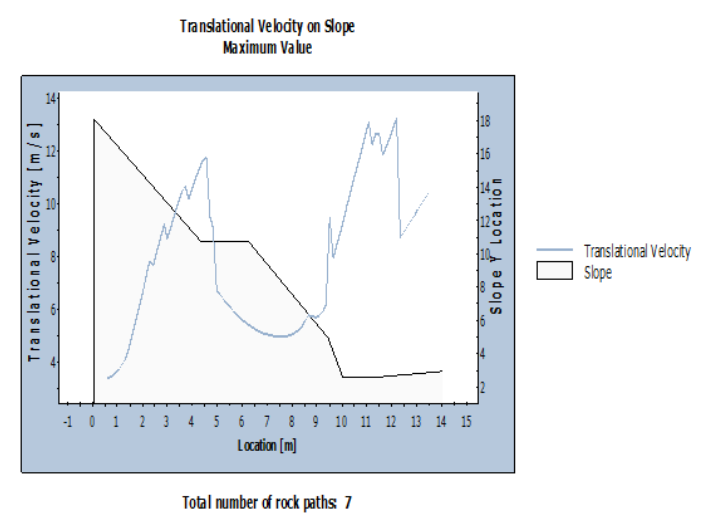

Figure21: Trajectory translational velocity envelope from RocFall 8.0 simulated results

Figure 22 to 25 show the rock fall modeling results of study location 6 .

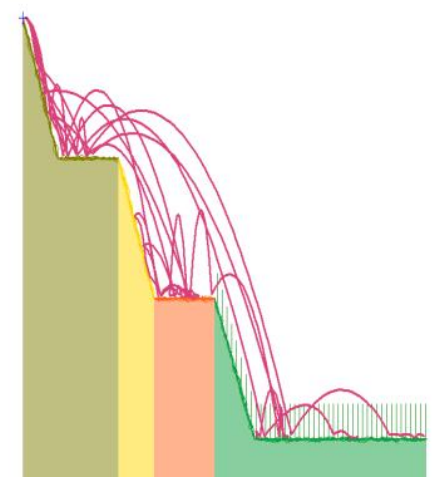

Figure22: Simulation of seven rock fall model

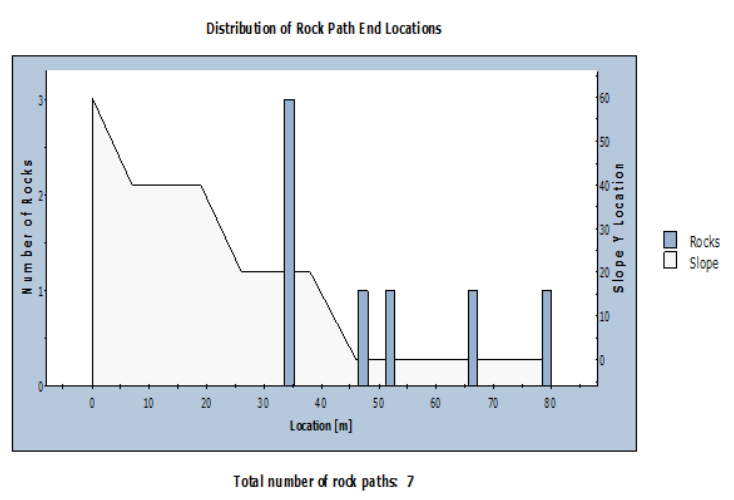

Figure23: Rock fall end location from RocFall 8.0 simulated results

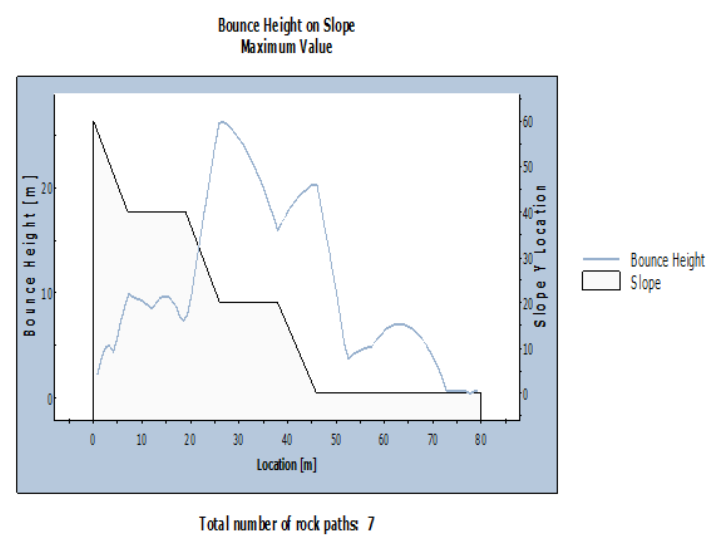

Figure24: Trajectory height envelope envelope from RocFall 8.0 simulated results 
Numerical Investigation of the Influence of Rockfall near Structures in Selected Southwestern States, Nigeria

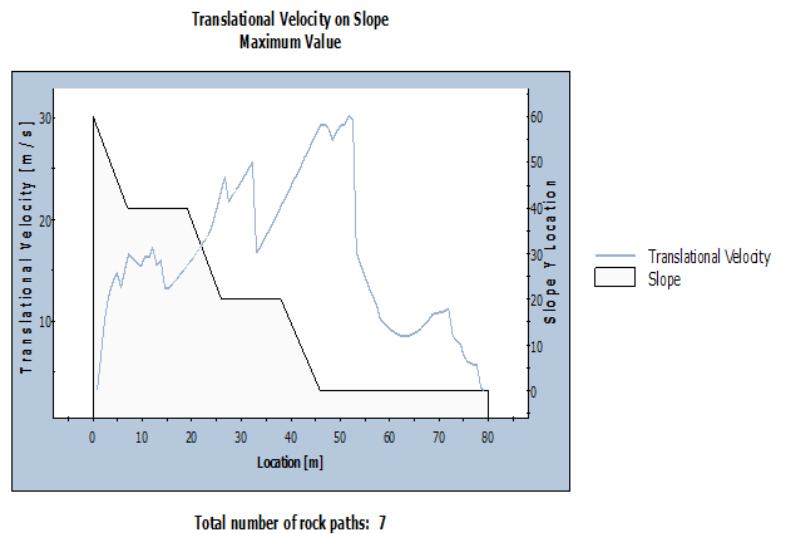

Figure25: Trajectory translational velocity from RocFall 8.0 simulated results

Figure 26 to 29 show the rock fall modeling results of study location 7.

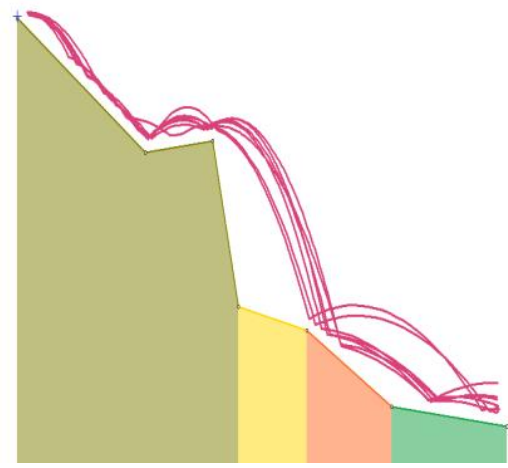

Figure26: Simulation of seven rockfall model

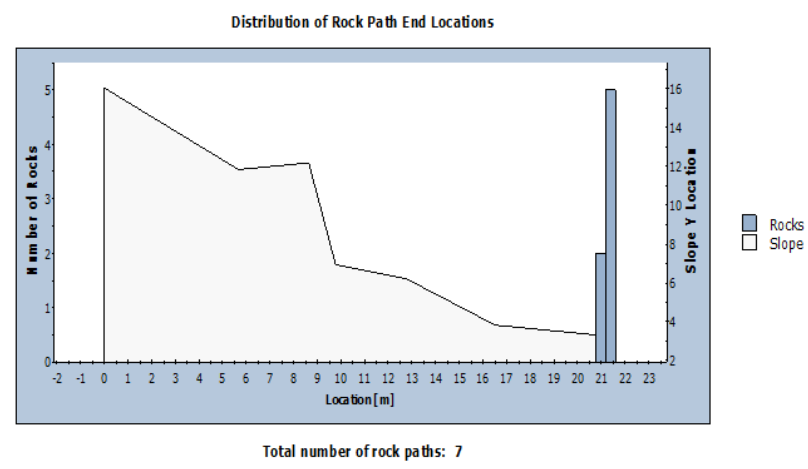

Figure27: Rock fall end location from RocFall 8.0 simulated results

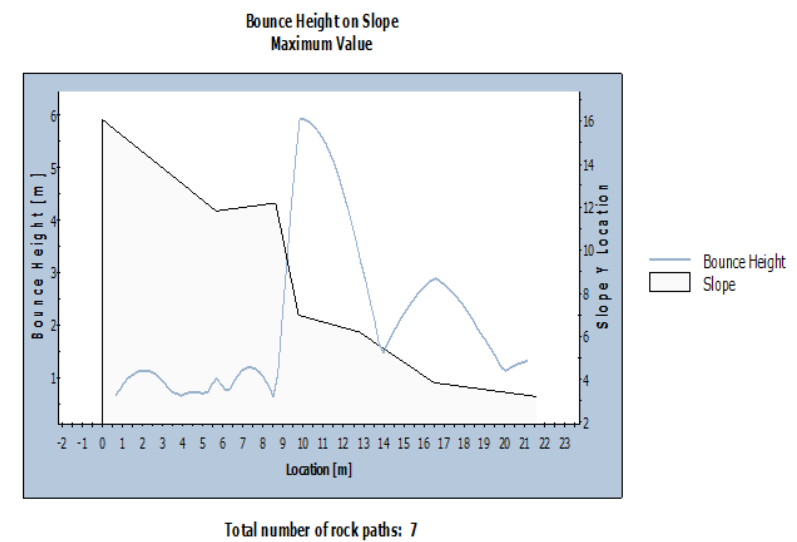

Figure28: Trajectory height envelope from RocFall 8.0 simulated results 


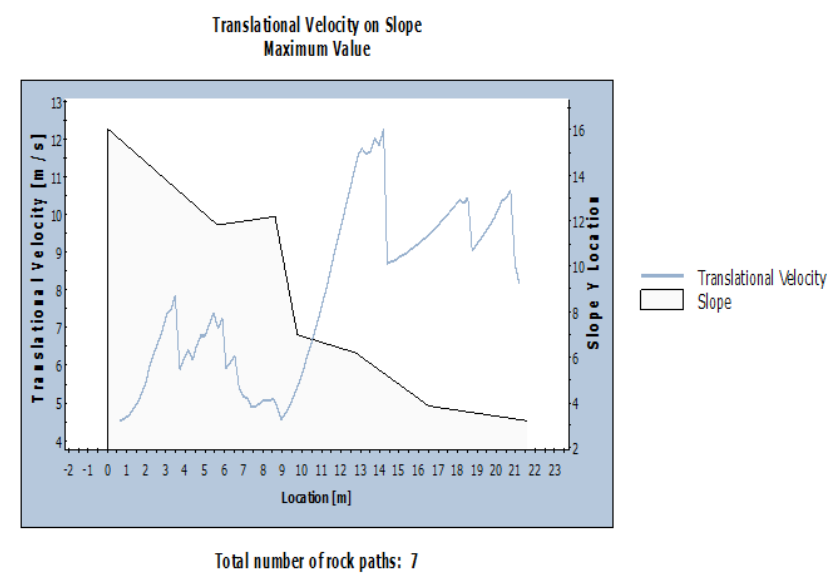

Figure29: Trajectory translational velocity envelope from RocFall 8.0 simulated results

Table2: Results of RocFall Program Simulation of the Study Area

\begin{tabular}{|l|l|l|l|l|l|l|l|}
\hline \multicolumn{1}{c|}{$\begin{array}{c}\text { Study } \\
\text { Location }\end{array}$} & \multicolumn{1}{|c|}{$\mathbf{1}$} & \multicolumn{1}{|c|}{$\mathbf{2}$} & \multicolumn{1}{|c|}{$\mathbf{3}$} & \multicolumn{1}{|c|}{$\mathbf{5}$} & $\mathbf{6}$ & $\mathbf{7}$ \\
\hline End Point (m) & $54.0-68.0$ & $11.9-14.6$ & 11.3 & $13.7-15.6$ & $4.7-13.6$ & $35.0-80.0$ & 21.5 \\
\hline $\begin{array}{l}\text { Max Bounce } \\
\text { Height (m) }\end{array}$ & 2.5 & 14.2 & 2.5 & 1.9 & 5.6 & 26.3 & 5.6 \\
\hline $\begin{array}{l}\text { Max Trans } \\
\text { velocity (m/s) }\end{array}$ & 19.0 & 16.4 & 10.4 & 9.7 & 12.9 & 30.1 & 12.3 \\
\hline
\end{tabular}

The results of RocFall program of seven locations analyzed and interpreted in terms of trajectory, motion, runout distance, bounce heights with translation velocity. The falling trajectories and their endpoints, bounce heights with translation velocity are shown in Figures $2-29$. Their trajectories are decided by the characteristics of the slope. Additional slope characteristics determine the end point of the falling rocks some stop along the slope while some travel farther downslope to reach the base of the slope. The simulation results summarize in Table 2 showed the end points of falls at each location and also showed that location 6 attained the highest maximum bouncing height with $26.3 \mathrm{~m}$ while, Location 4 attained the lowest maximum bouncing height with $1.9 \mathrm{~m}$ as compared to other locations.

\subsection{Rock Fall Impact on Barrier Modelling}

Observations of rock fall impacts on the barrier provided reliable information on the impact velocity and energy. In this model, all the rock falls that reached the barrier location in each study location were contained by the barrier so it was not possible to use the back analysis feature in RocFall 8.0.

Figures 30 and 31 show the rock fall impact in study location 1.
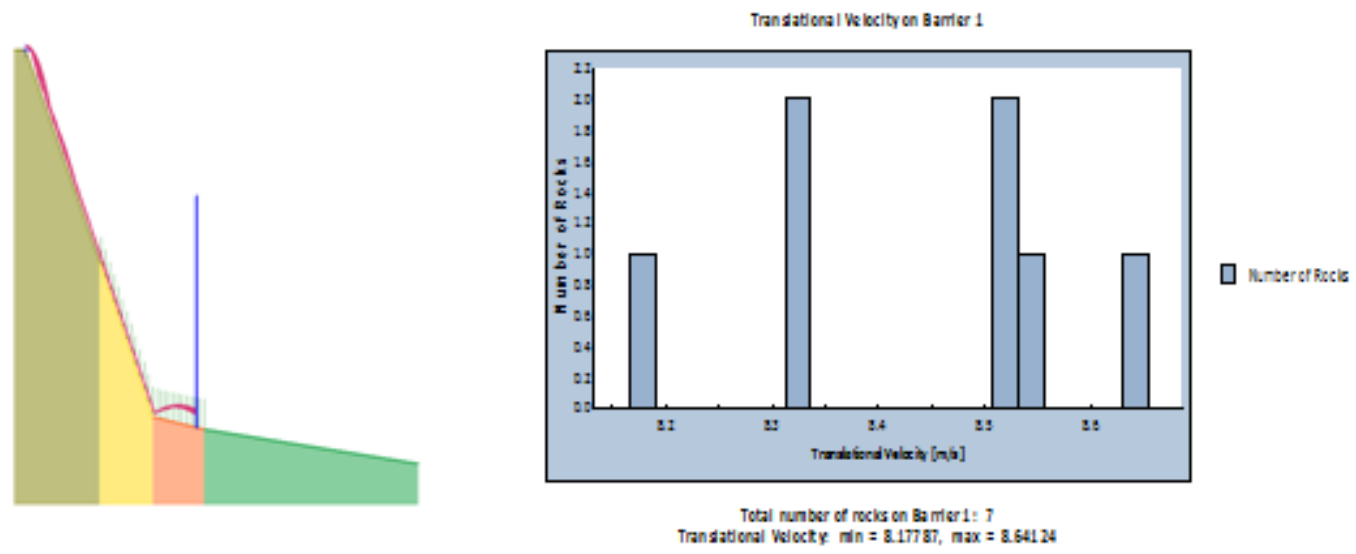

(a)

Figure30: Trajectory of falls that impacted the barrier. 
Numerical Investigation of the Influence of Rockfall near Structures in Selected Southwestern States, Nigeria

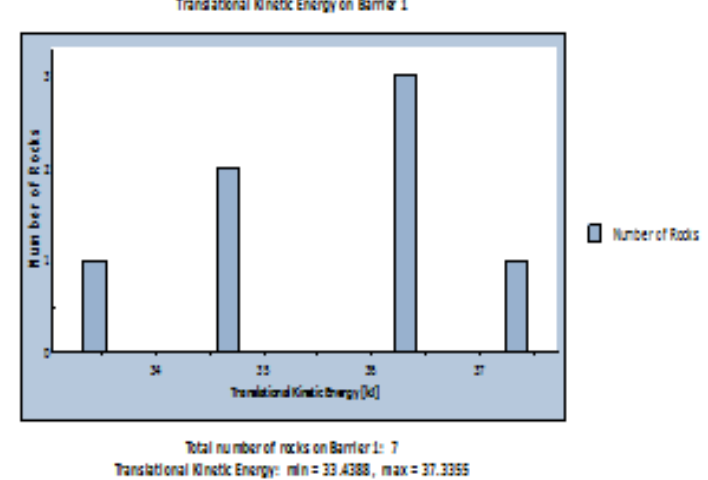

(b)

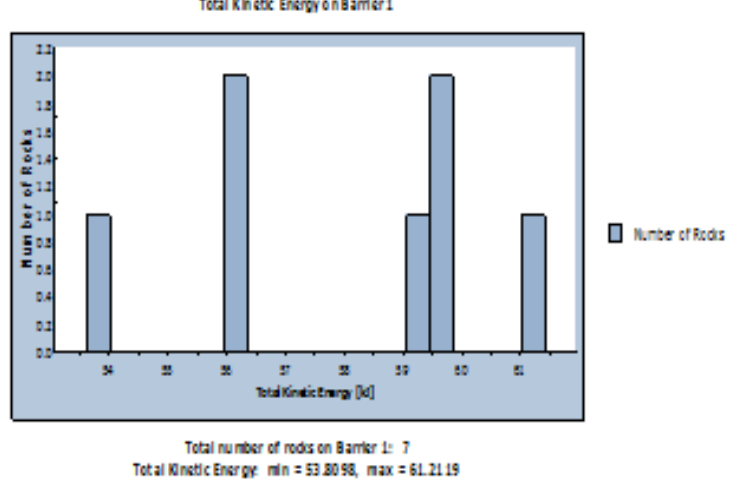

(c)

Figure31: Analysis falls on barrier at location 1 (a) translational velocity distribution; $(b)$ translational kinetic energy distribution; (c) total energy distribution.

Figures 32 and 33 show the rock fall impact in study location 2.

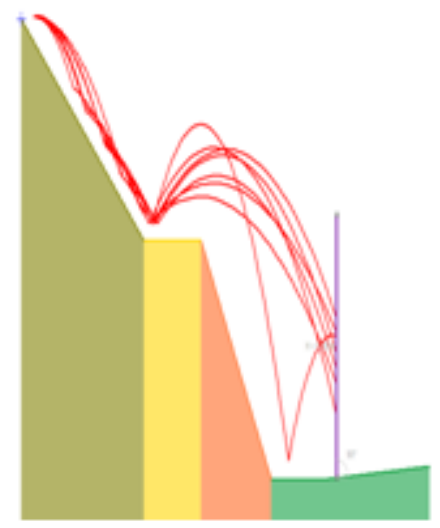

(a)

Figure32: trajectory of falls that impacted the barrier.

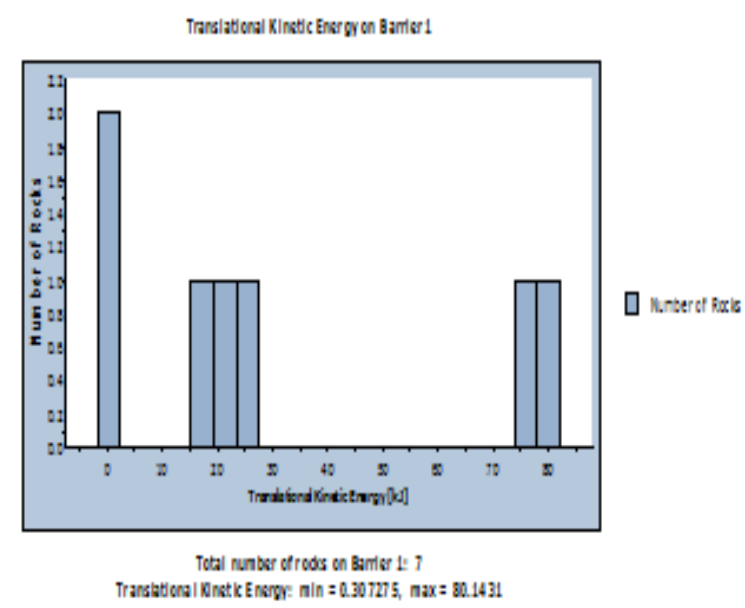

(b)

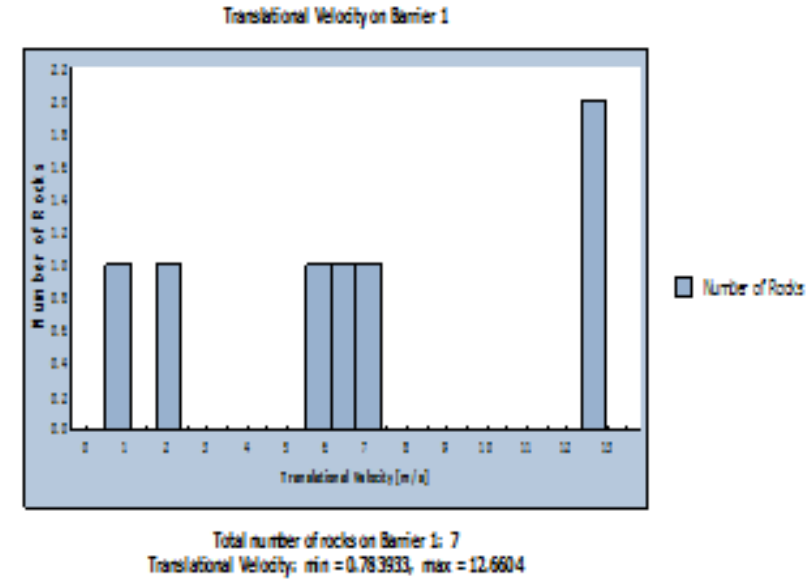

)

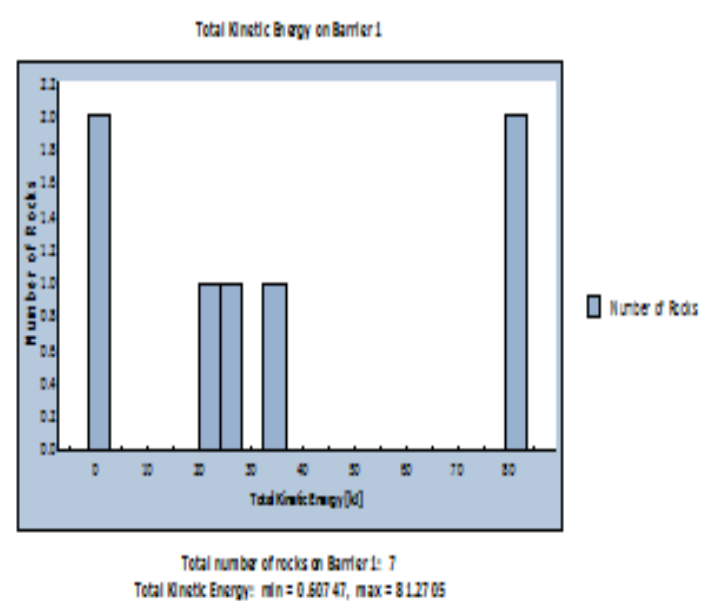

(c)

Figure33: Analysis of falls on barrier at location 2 (a) translational velocity distribution; (b) translational kinetic energy distribution; (c) total energy distribution.

Figures 34 and35 show the rock fall impact in study location 3. 
Numerical Investigation of the Influence of Rockfall near Structures in Selected Southwestern States, Nigeria
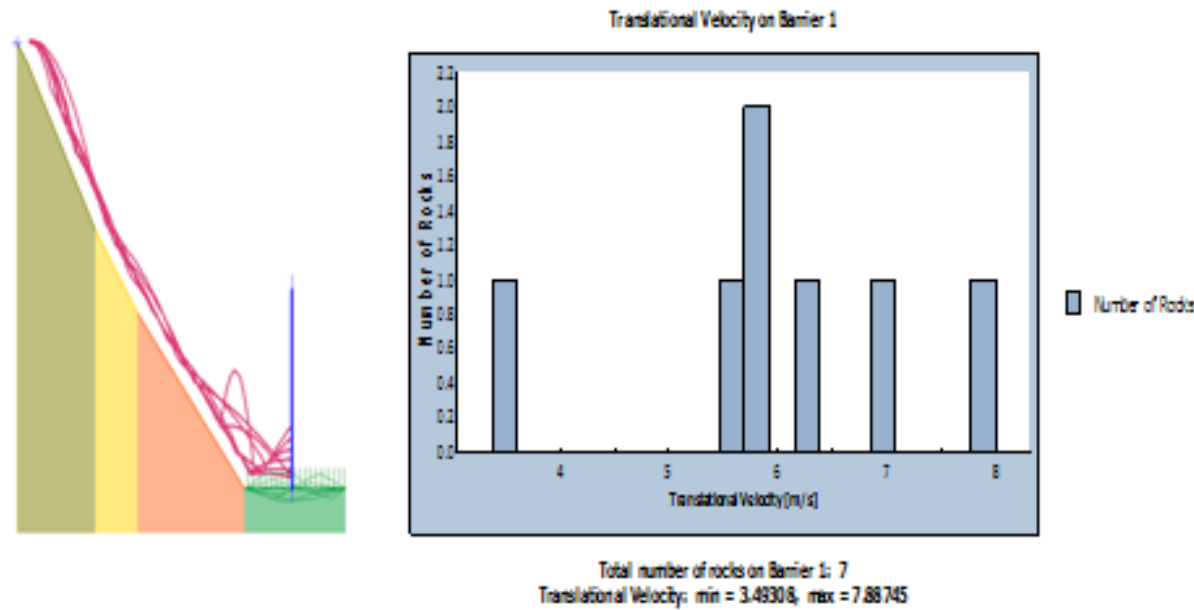

(a)

Figure34: trajectory of falls that impacted the barrier.

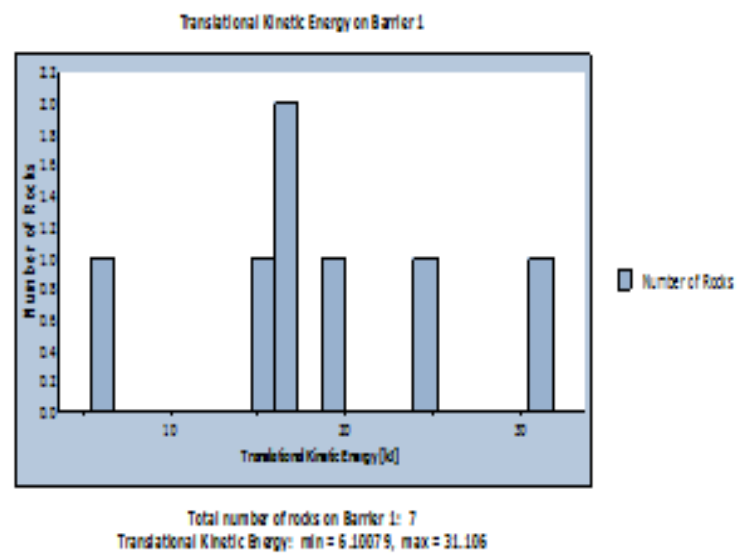

(b)

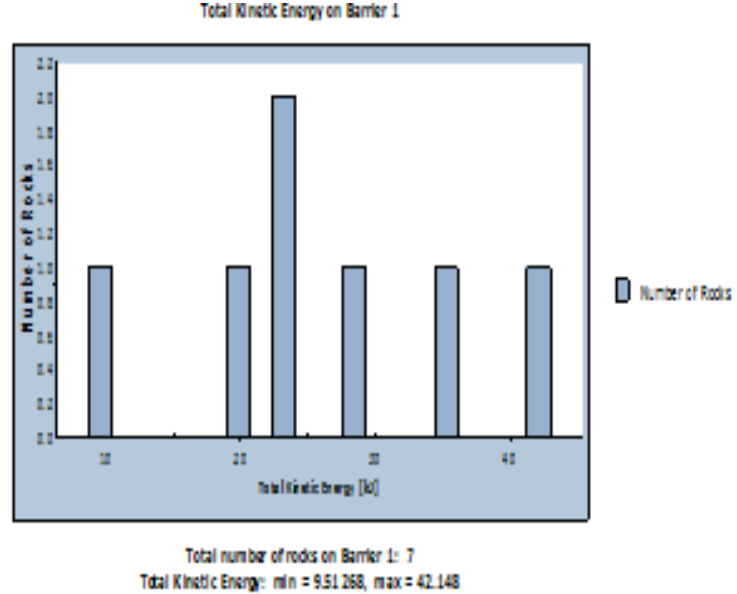

(c)

Figure35: Analysis of falls on barrier at location 3 (a) translational velocity distribution; (b) translational kinetic energy distribution; (c) total energy distribution.

Figures 36 and 37 show the rock fall impact in study location 4.
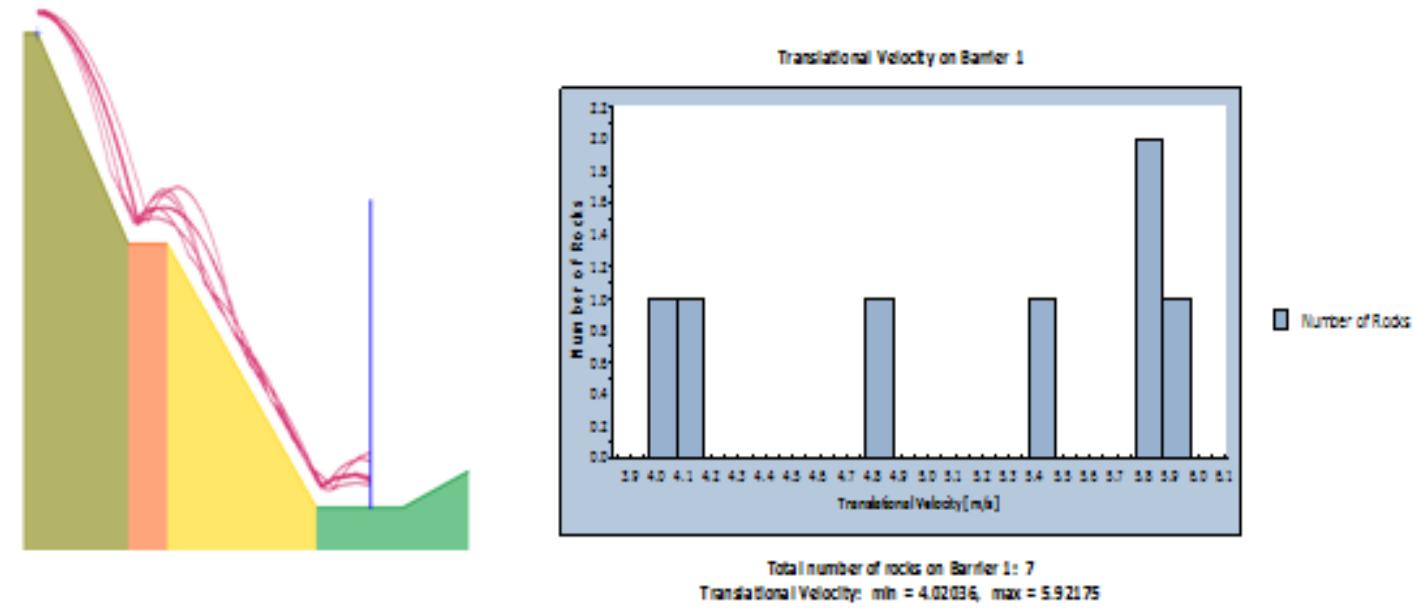

(a)

Figure36: Accumulation of falls that impacted the barrier. 
Numerical Investigation of the Influence of Rockfall near Structures in Selected Southwestern States, Nigeria

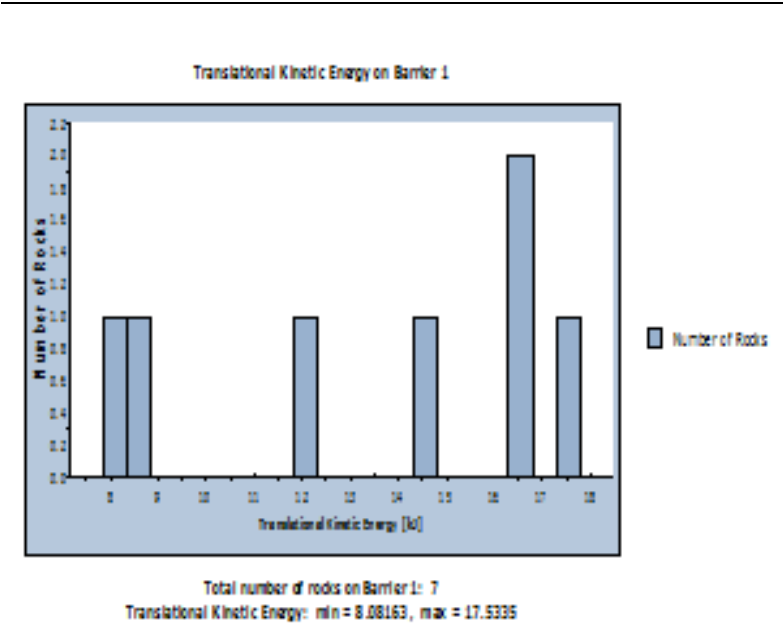

(b)

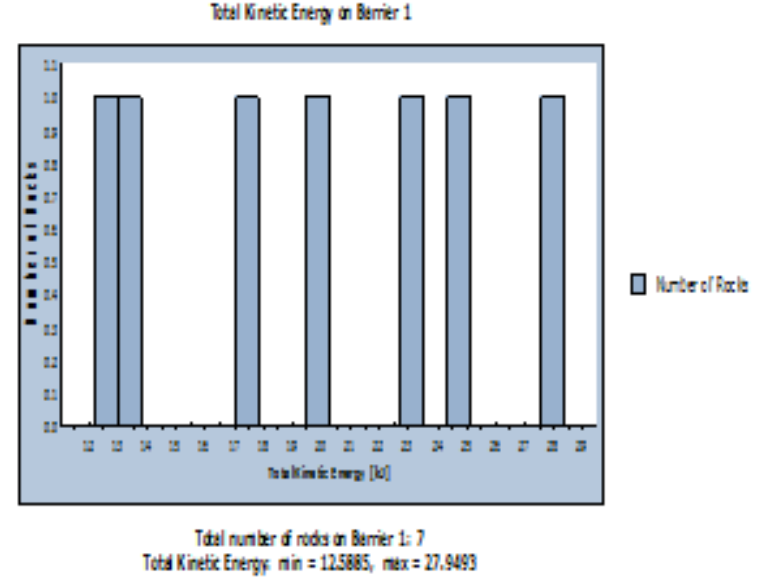

(c)

Figure37: Analysis of falls on barrier at location 4 (a) translational velocity distribution; (b) translational kinetic energy distribution; (c) total energy distribution.

Figures 38 and 39 show the rock fall impact in study location 5.
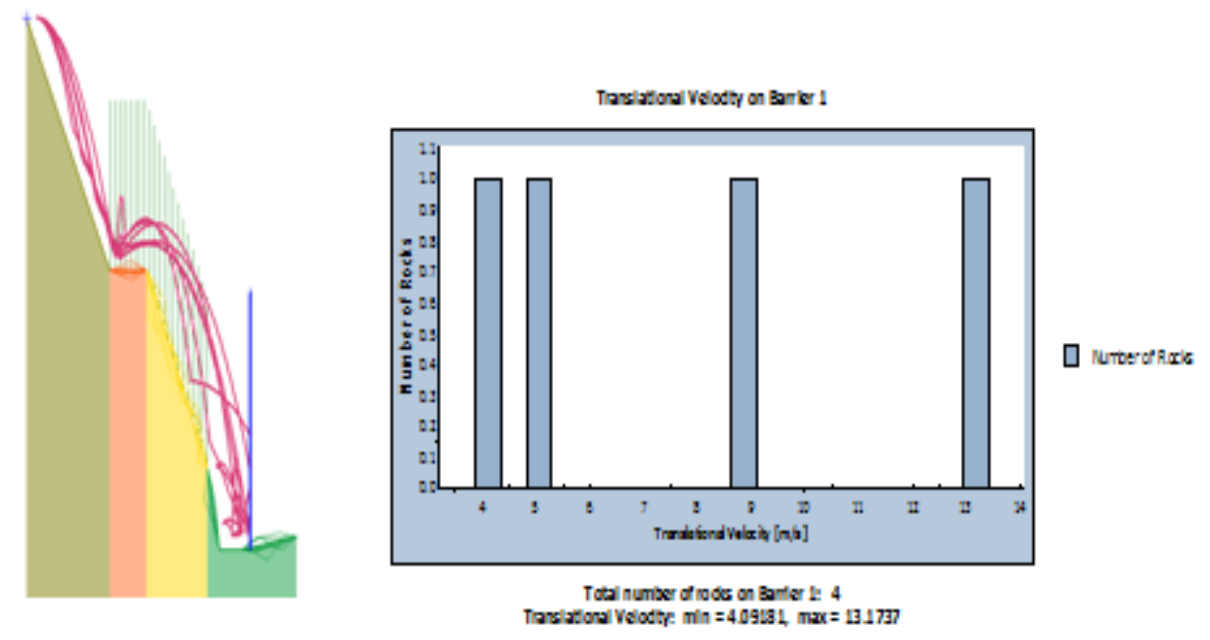

(a)

Figure38: Accumulation of falls that impacted the barrier.

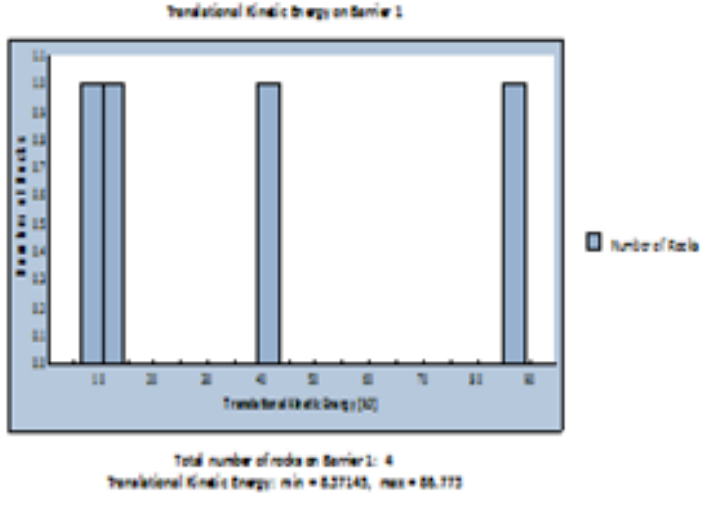

(b)

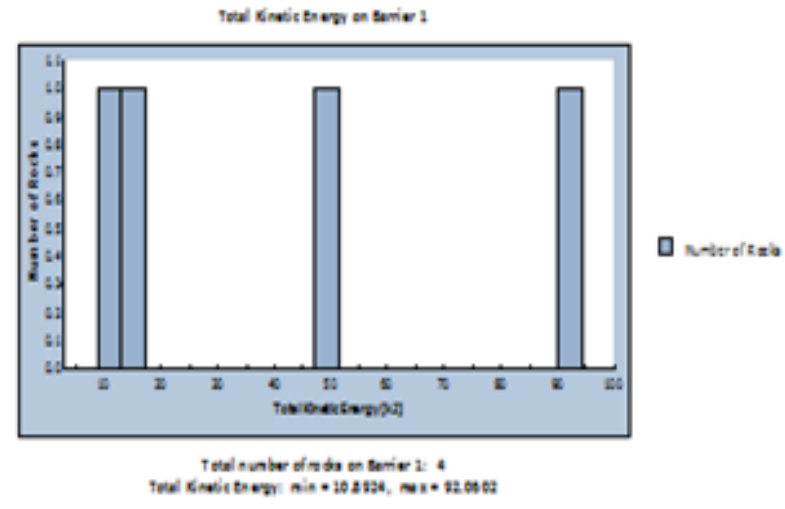

(c)

Figure39: Analysis of falls on barrier at location 5 (a) translational velocity distribution; (b) translational kinetic energy distribution; (c) total energy distribution. 
Numerical Investigation of the Influence of Rockfall near Structures in Selected Southwestern States, Nigeria

Figures 30 and 31 show the rock fall impact in study location 6.
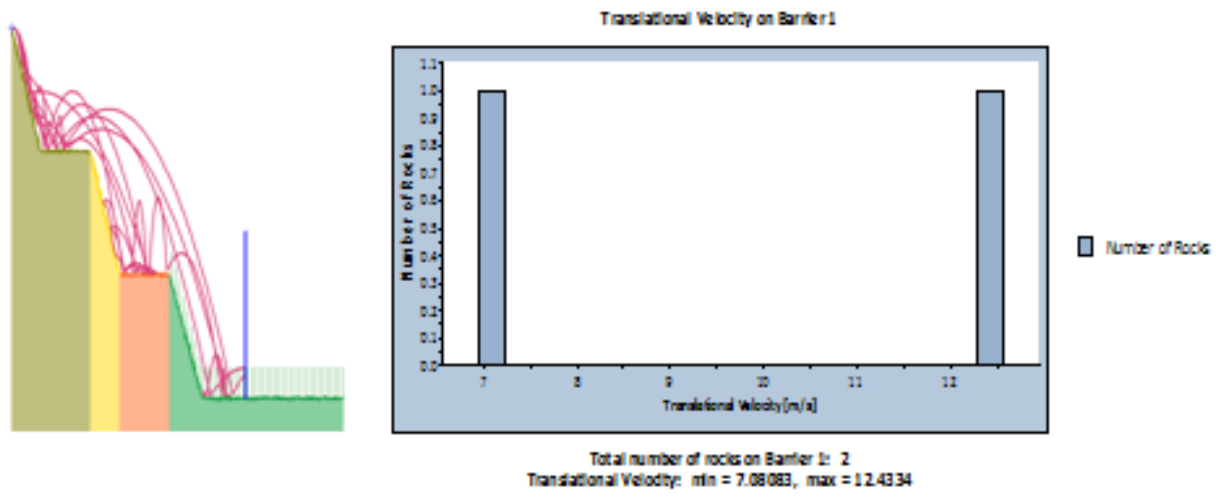

(a)

Figure31: Accumulation of falls that impacted the barrier.

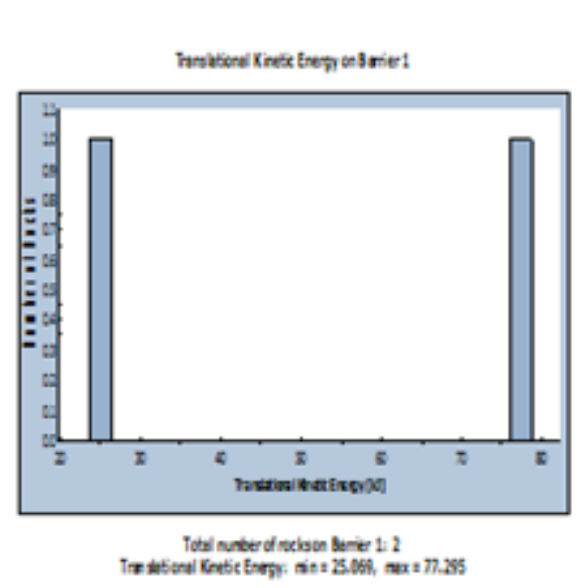

(b)

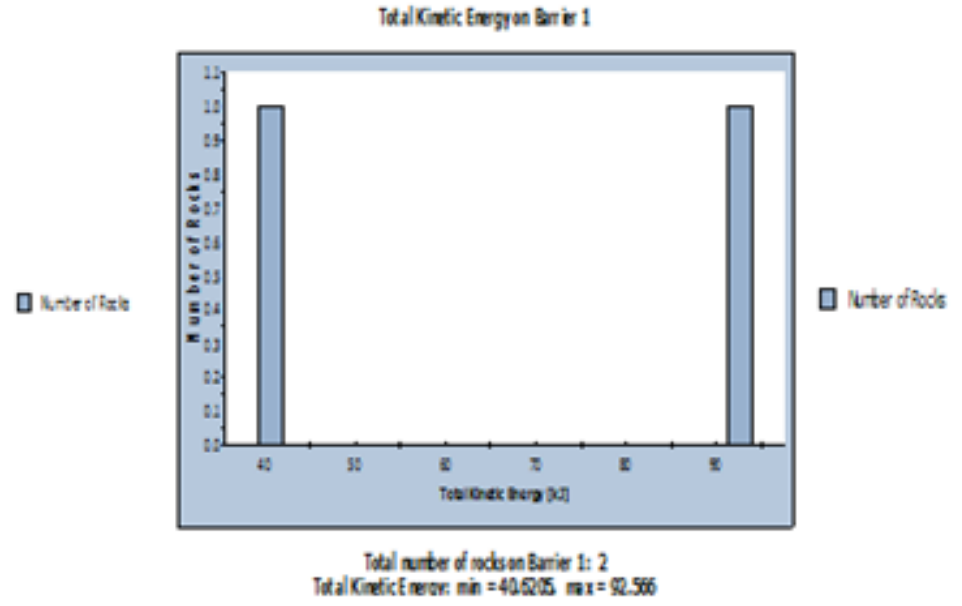

(c)

Figure31: Analysis of falls on barrier at location 6 (a) translational velocity distribution; (b) translational kinetic energy distribution; (c) total energy distribution.

Figures 32 and 33 show the rock fall impact in study location 7.
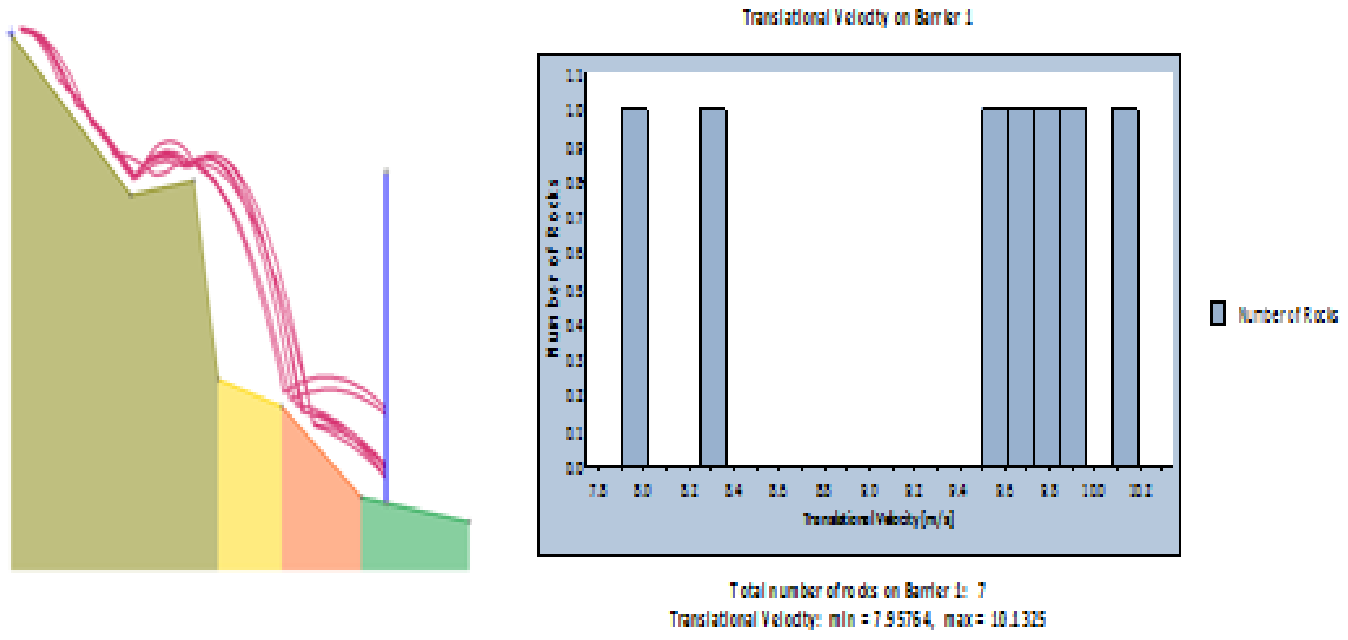

(a)

Figure32: Accumulation of falls that impacted the barrier. 
Numerical Investigation of the Influence of Rockfall near Structures in Selected Southwestern States, Nigeria

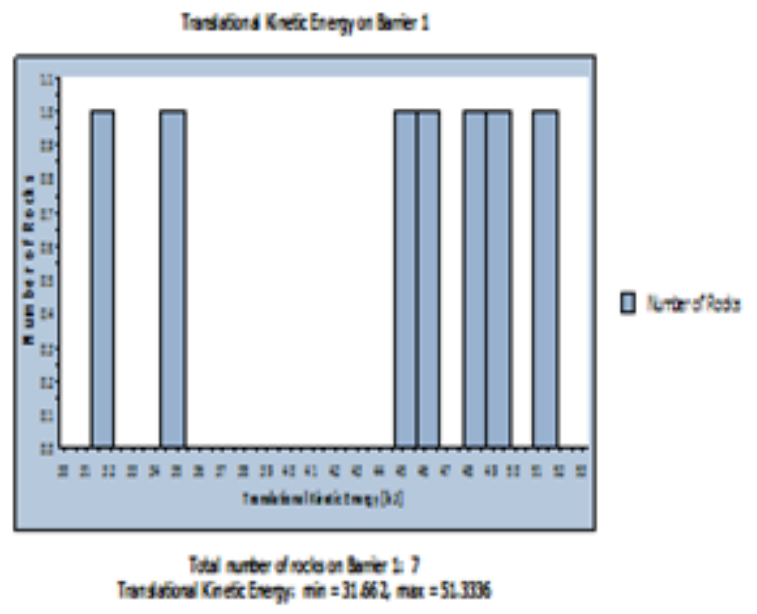

(b)

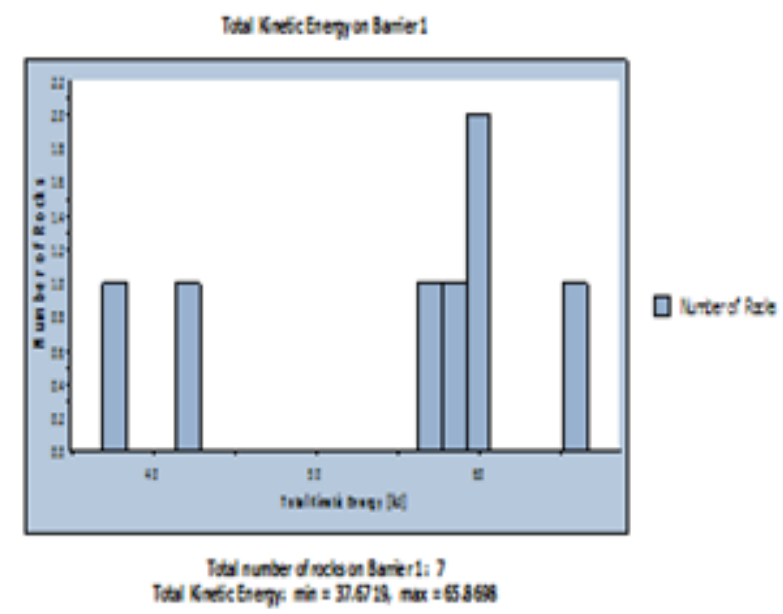

(c)

Figure33: Analysis of falls on barrier at location 7 (a) translational velocity distribution; (b) translational kinetic energy distribution; (c) total energy distribution.

Table3: Results of Rock Fall Impacts on Barrier in Each Study Location

\begin{tabular}{|l|l|l|l|l|l|l|l|}
\hline \multirow{2}{*}{$\begin{array}{c}\text { Study } \\
\text { Location }\end{array}$} & \multicolumn{2}{|c|}{$\begin{array}{c}\text { Translational Velocity } \\
(\mathbf{m} / \mathbf{s})\end{array}$} & \multicolumn{2}{c|}{$\begin{array}{c}\text { Translational Kinetic } \\
\text { Energy }\end{array}$} & \multicolumn{2}{c|}{$\begin{array}{c}\text { Total Kinetic Energy } \\
(\mathbf{k J})\end{array}$} & \multicolumn{1}{c|}{$\begin{array}{c}\text { Max } \\
\text { Intensity } \\
\text { Level Zone }\end{array}$} \\
\cline { 2 - 7 } & \multicolumn{1}{|c|}{ Min } & \multicolumn{1}{|c|}{ Max } & \multicolumn{1}{|c|}{ Max } & Min & & \\
\hline 1 & 8.17787 & 8.64124 & 33.4388 & 37.3355 & 53.8098 & 61.2119 & Medium \\
\hline 2 & 0.7839933 & 12.6604 & 0.307275 & 80.1431 & 0.60747 & 81.2705 & Medium \\
\hline 3 & 3.49308 & 7.88745 & 6.10079 & 31.106 & 9.51268 & 42.148 & Medium \\
\hline 4 & 4.02036 & 5.92175 & 8.08163 & 17.5335 & 12.5885 & 27.9493 & Low \\
\hline 5 & 4.09181 & 13.1737 & 8.37145 & 86.773 & 10.8924 & 92.0602 & Medium \\
\hline 6 & 7.08083 & 12.4334 & 25.069 & 77.295 & 40.6205 & 92.566 & Medium \\
\hline 7 & 7.95764 & 10.1325 & 31.662 & 51.336 & 37.6719 & 65.86 .98 & Medium \\
\hline
\end{tabular}

Previous researches established the used of total kinetic energy values obtained from rock fall analysis to characterize the damage capacity of rock falls into three groups which are; high (> $300 \mathrm{~kJ})$, medium $(30-300 \mathrm{~kJ})$, and low intensity $(<30 \mathrm{~kJ})$. Therefore, an attempt to predict rock fall hazard zoning based on the total kinetic energy for this study by classifying the intensity hazard level zone, the results of rock fall model of each location summarized in Table 3 showed location 1, 2, 3, 5, 6 and 7 at the medium intensity hazard level zone, while location 4 marked at low intensity hazard level zone.

\section{Conclusion}

In conclusion, the influence of rockfall by predicting the intensity hazard level zone in the study area show that study location 1, 2, 3, 5, 6 and 7 has respectively, total kinetic energy of approximately 61.2 $\mathrm{kJ}, 81.3 \mathrm{~kJ}, 42.1 \mathrm{~kJ}, 92.1 \mathrm{~kJ}, 92.6 \mathrm{~kJ}$ and $65,9 \mathrm{~kJ}$ which pose risk of medium intensity hazard level zone, while study location 4 which has total kinetic energy of $27.9 \mathrm{~kJ}$ is at risk of low intensity hazard level zone. Although, rock fall influence capable of causing motality and damaging structures should also be expected in areas with low intensity hazard level zone. Therefore, barriers with capacity $>300$ $\mathrm{kJ}$ is required to adequately mitigate/handle the influence/vulnerability of rockfall in the study area.

\section{REFERENCES}

[1] Agliardi F. and Crosta G. B. (2003). High Resolution Three-Dimensional Numerical Modelling of Rockfalls. International Journal of Rock Mechanics and Mining Science 40, pp. 455-471.

[2] Agliardi F., Crosta G.B. and Frattini P. (2009). Integrating rockfall risk assessment and countermeasure design by 3D modelling techniques. Natural Hazard and Earth Systems Science Journal, 9, pp. 1059-1073.

[3] Ahmad M.,Umrao R. K., Ansari M. K., Singh R. and Singh T. N. (2013). Assessment of Rockfall Hazard along the Road Cut Slopes of State Highway-72, Maharashtra, India. Journal of Geomaterials, 3(1), pp. 15-23. 
Numerical Investigation of the Influence of Rockfall near Structures in Selected Southwestern States, Nigeria

[4] An B. and Tannant D. (2007). Discrete element method contact model for dynamic simulation of inelastic rock impact.Computers and Geosciences, 33(4), pp. 513-521.

[5] Ansari M. K., Ahmad M., Singh R and Singh T. N. (2018). 2D and 3D Rock Fall Hazard Analysis and Protection Measures for Saptashrungi Gad Temple, Vani, Nashik, Maharashtra a case study. Journal of Geological Society of India, 94, pp. 47-56.

[6] Bourrier F. and Hungr O. (2013).Rockfall Dynamics, a Critical Review of Collision and Rebound Models. In Lambert S. and Nicot F. (Eds.), Rockfall Engineering John wiley\& Sons, Inc., Hoboken, NJ, USA, pp. 175-209.

[7] Bozzolo D., and Pamini R. (1986).Simulation of rock falls down a valley side. ActaMechanica, 63(1), pp. 113-130.

[8] Crosta G.B., Agliadi F., Frattini P. and Lari S. (2015). Key Issues in Rock Fall Modelling, Hazard and Risk Assessment for RockFall Protection. G. Lollino et al. (Eds.), Journal of Engineering Geology for Society and Territory, 2, pp. 43-57.

[9] Crosta, G., Agliardi, F. (2003). A methodology for physically based rockfall hazard assessment. Natural Hazard and Earth Systems Science, 3, pp. 407-422.

[10] De Blasio F. and Crosta G. B. (2015). Fragmentation and Boosting of Rock Falls and Rock Avalanches, Geophysical Res. Lett., 42, pp. 8463-8470.

[11] Dorren L. K. A. (2003). A review of rockfall mechanics and modelling approaches. Progress in Physical Geography, 27(1), pp. 69-87.

[12] Giacomini A., Buzzi O., Renard B. and Giani G.P. (2009). Experimental Studies on Fragmentation of Rock Falls on Impact with Rock Surfaces. International Journal of Rock Mechacnics and Mining Science 46, pp. 708-715.

[13] Giani G. P., Giacomini A., Migliazza M., and Segalini A. (2004). Experimental and Theoretical Studies to Improve Rock Fall Analysis and Protection Work Design. Rock Mechanics and Rock Engineering, 37(5), pp. 369-389.

[14] Guzzetti F., Crosta G., Detti R., and Agliardi F. (2002).STONE: a computer program for the threedimensional simulation of rock-falls. Computers \& Geosciences Journal, 28(9), pp. 1079-1093.

[15] Jaboyedoff M. and Labiouse V. (2011). Technical note: preliminary estimation of rockfall runout zones. Natural Hazard and Earth Systems Science Journal, 11, pp. 819-828.

[16] Jaboyedoff M., Dudt J.P. and Labiouse V. (2005). An attempt to refine rockfall hazard zoning based on the kinetic energy, frequency and fragmentation degreeNatural Hazard and Earth Systems Science Journal, 5, pp. 621-632

[17] Lateltin O, Haemmig C, Raetzo H, Bonnard C. (2005). Landslide risk management in Switzerland. Landslides. 2, pp. 313-320.

[18] Lee K. and Elliott G. (1998). Rockfall: Application of Computer Simulation to Design of Preventive Measures, Planning, Design and Implementation of Debris Flow and Rock Fall Hazards Mitigation Measures, Association of Geo-Technical Specialists and Hong Kong Institution of Engineers, Hong Kong.

[19] Legros F. (2002). The mobility of long-runout landslides, Journal of Engineering Geology, 63(3-4), pp. 301-331.

[20] Lo C. M., Feng Z. Y., and Chang K. T. (2018). Landslide Hazard Zoning Based on Numerical Simulation and Hazard Assessment, Journal of Geomatics Natural Hazards and Risk, 9 (1), pp. 368-388,

[21] Mougin J.-P., Perrotin P., Mommessin M., Tonnelo J., and Agbossou A. (2005). Rock fall impact on reinforced concrete slab: an experimental approach. International Journal of Impact Engineering, 31(2), pp. 169-183.

[22] Nocilla N., Evangelista A., and Scotto di Santolo A. (2008). Fragmentation during Rock Falls: Two Italian Case Studies of Hard and Soft Rocks. Rock Mechanics and Rock Engineering, 42(5), pp. 815-833

[23] Raetzo H., Lateltin O., Bollinger D. and Tripet J. P. (2002). Hazard Assessment in Switzerland Codes of Practice for Mass Movements; Bulletin of Engineering Geology and the Environment, 61, pp. 263-268.

[24] Volkwein A., Schellenberg K., Labiouse V., Agliardi F., Berger F., Bourrier F., Dorren L.K.A., Gerber W. and Jaboyedoff M. (2011).Rockfall characterisation and structural protection - a review. Natural Hazard and Earth Systems Science Journal, 11, pp. 2617-2651.

[25] Zhou X. P. and Cheng H. (2013). Analysis of Stability of Three Dimensional Slopes Using the Rigorous Limit Equilibrium Method, Journal of Engineering Geology, 160, pp. 21- 33. 
Numerical Investigation of the Influence of Rockfall near Structures in Selected Southwestern States, Nigeria

MAPOF NIGERIA SHOWING THE STUDY AREA AND UNDERLYTNG GEOLOGY

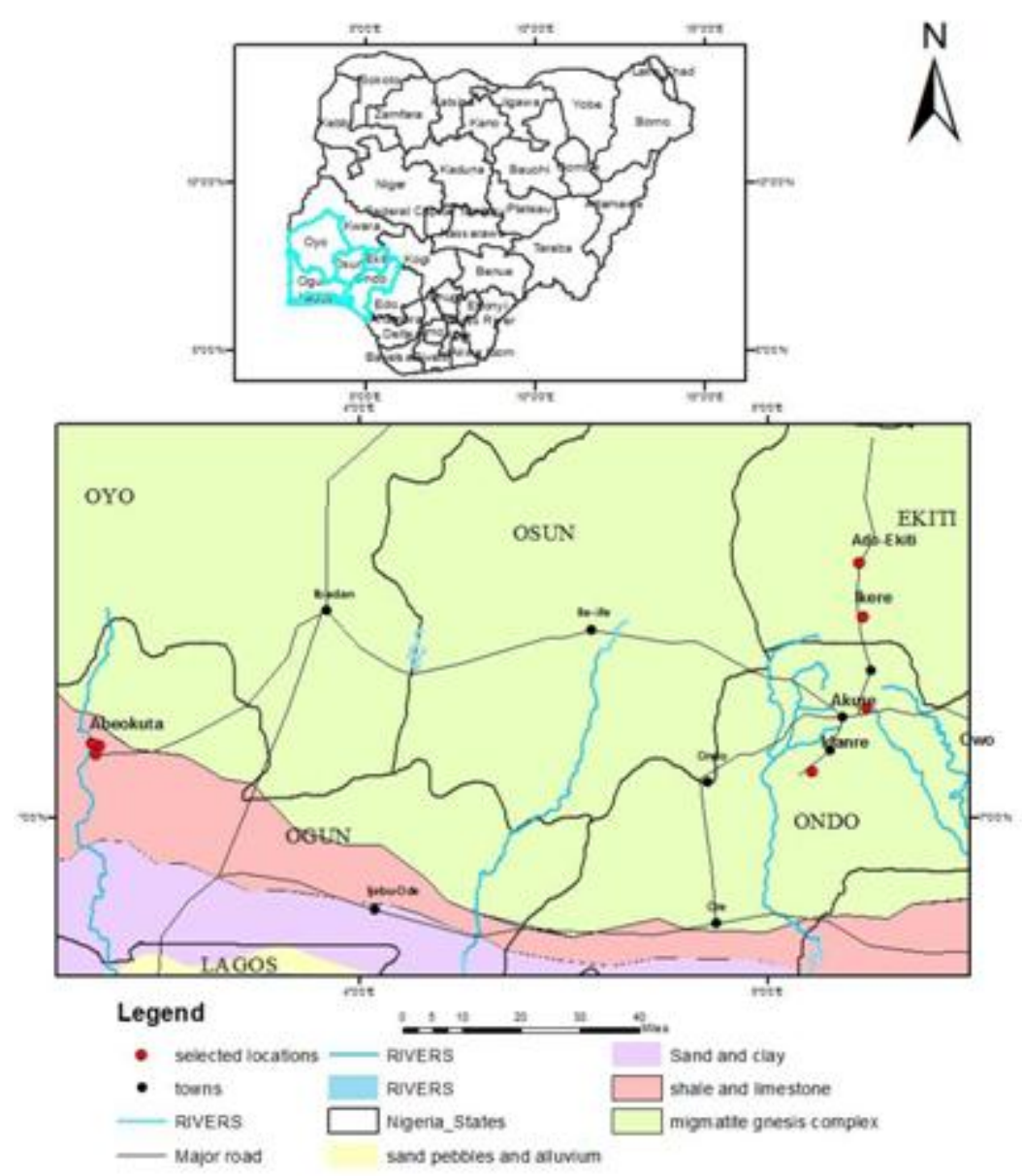

Figure 34: Geological map of the study locations (NGSA)

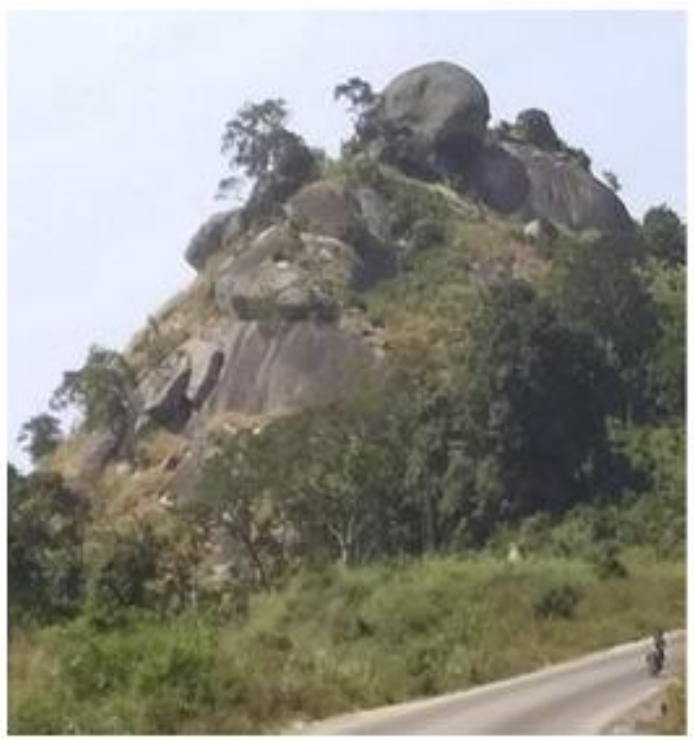

Platel: Pictorial view of study location 1

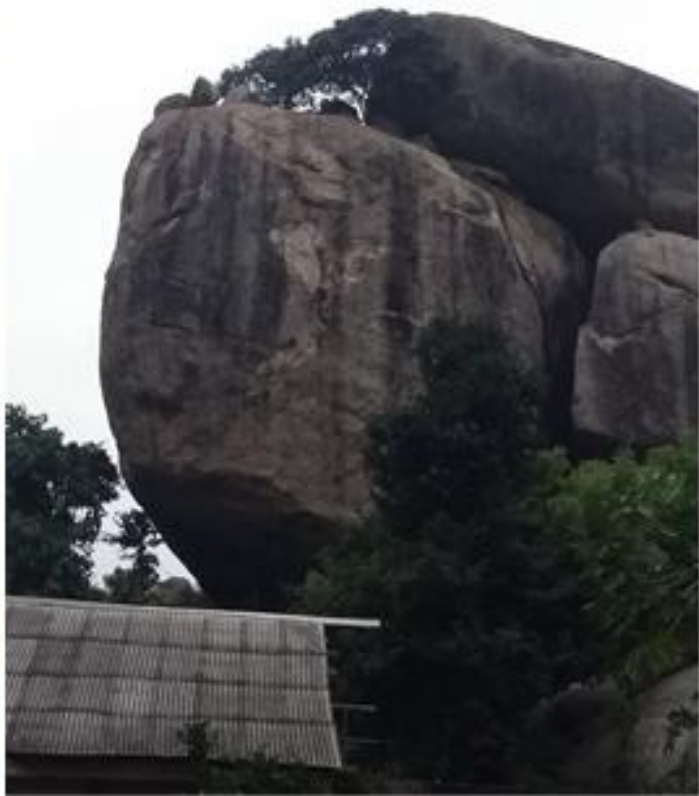

Plate 2: Pictorial view of study bcation 2 

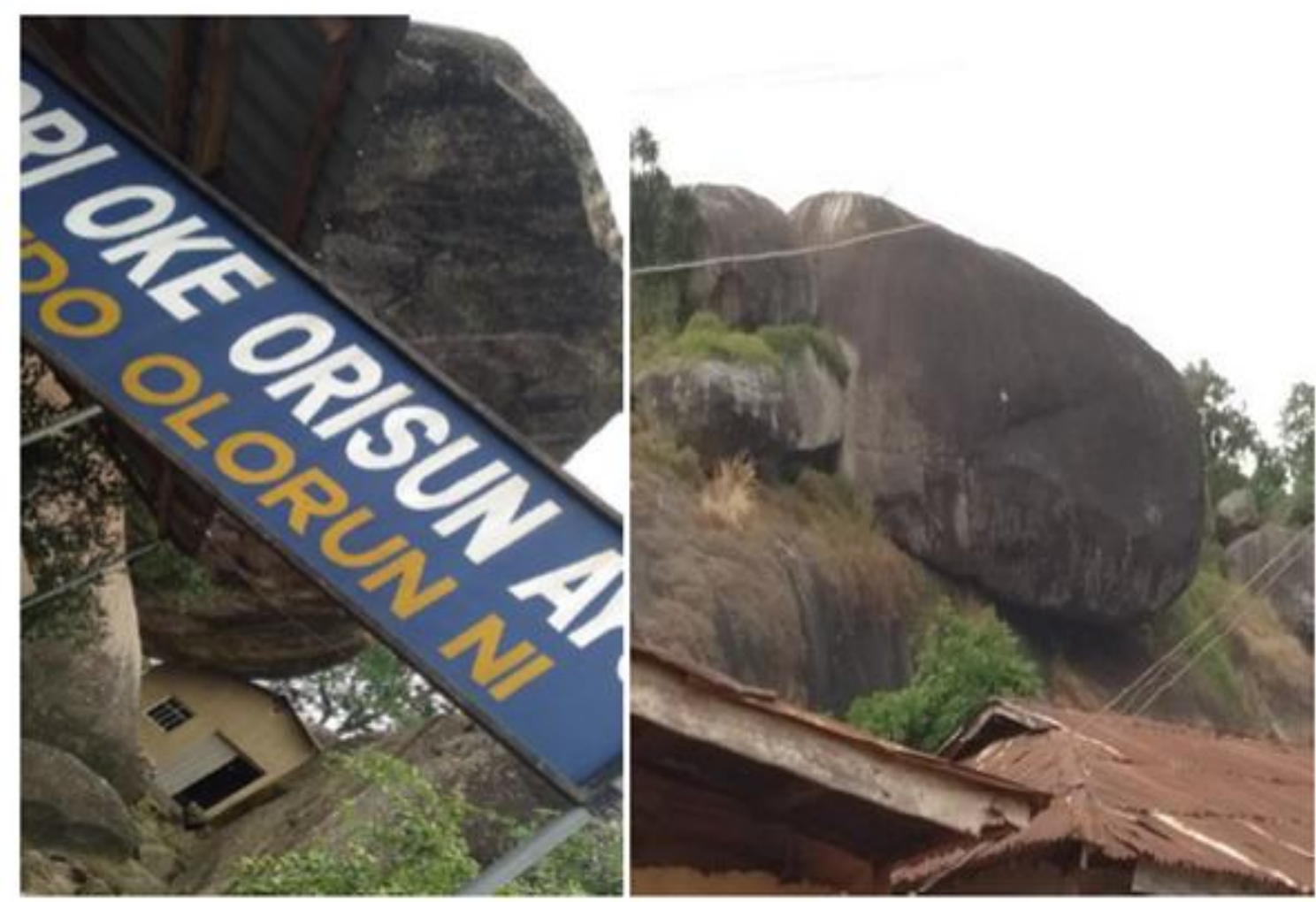

Plate 3: Pictorial view of study location 3 Plate 4: Pictorial view of study location 4

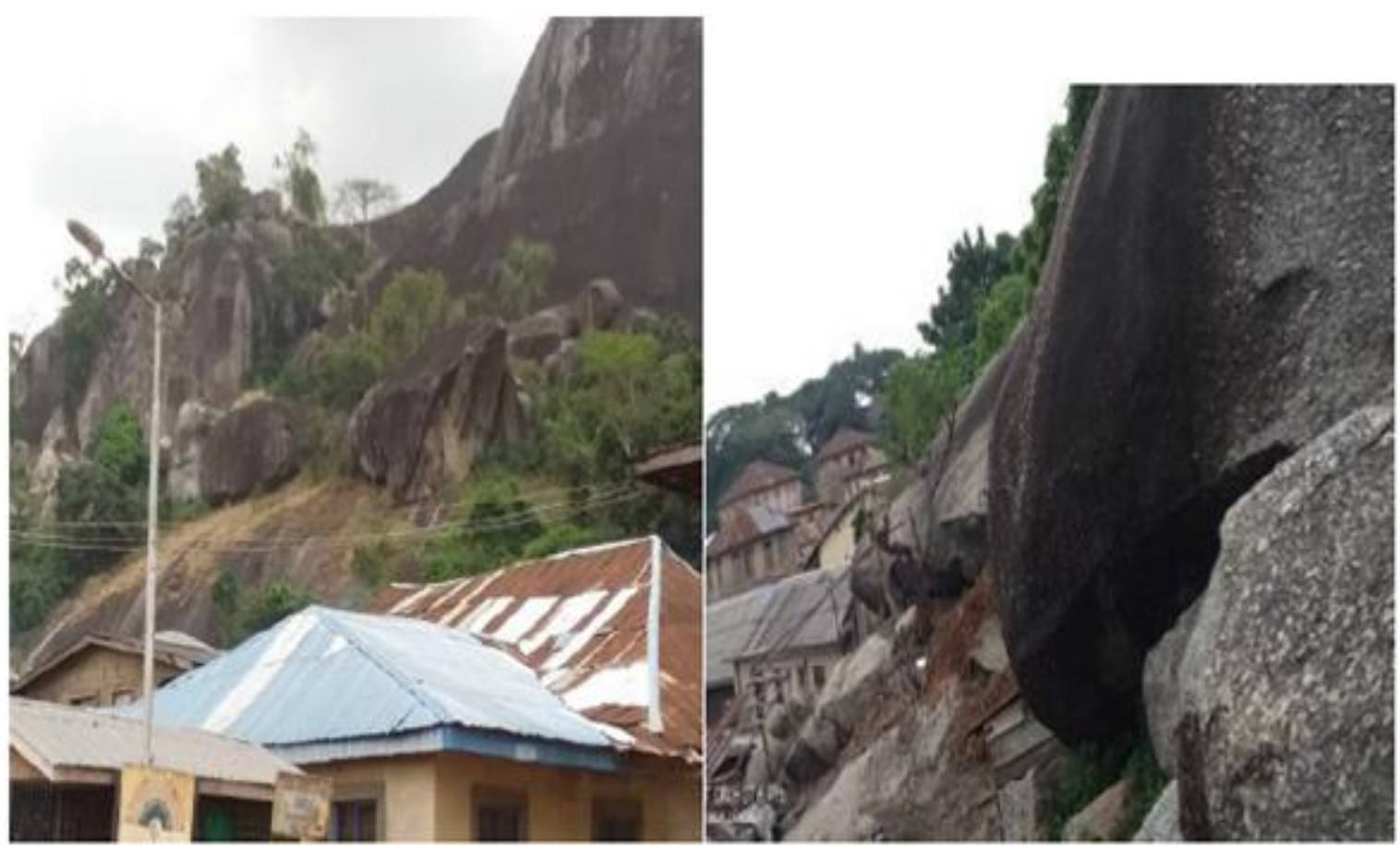

Plate 5: Pictorial view of study location 5

Plate 6: Pictorial view of study location 6 
Numerical Investigation of the Influence of Rockfall near Structures in Selected Southwestern States, Nigeria

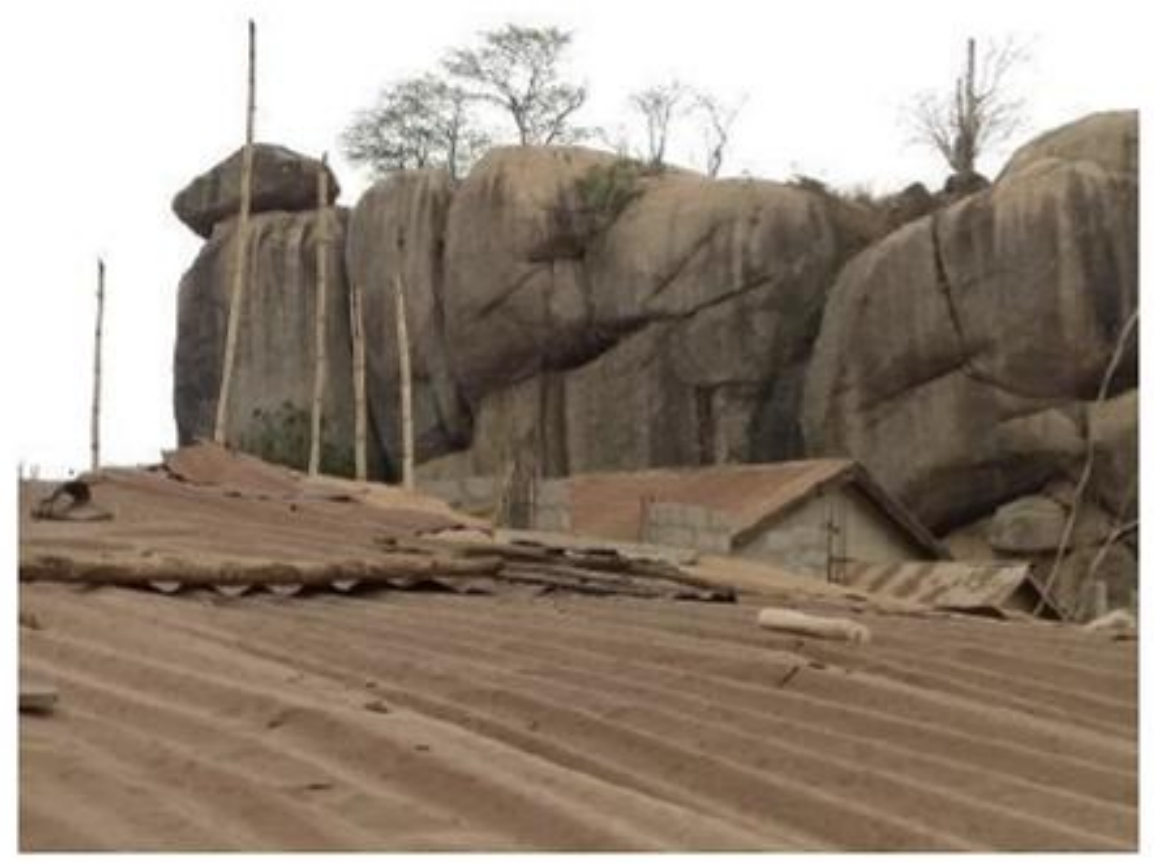

Plate 7: Pictorial view of study Location 7

Citation: Oniyide G.O*, Omoegun S.O, (2021)" Numerical Investigation of the Influence of Rockfall near Structures in Selected Southwestern States, Nigeria" $n$, International Journal of Mining Science (IJMS), 7(1), pp.53-72, DOI: http://doi.org/10.20431/2454-9460.0701005

Copyright: () 2021 Authors. This is an open-access article distributed under the terms of the Creative Commons Attribution License, which permits unrestricted use, distribution, and reproduction in any medium, provided the original author and source are credited 